\title{
Synthesis of Heptaprenyl-Lipid IV to Analyze Peptidoglycan Glycosyltransferases
}

\author{
Yi Zhang ${ }^{\dagger}$, Eric J. Fechter ${ }^{\dagger}$, Tsung-Shing Andrew Wang ${ }^{\dagger, *}$, Dianah Barrett, \\ Suzanne Walker ${ }^{* * *}$, and Daniel E. Kahne*t \\ Department of Chemistry and Chemical Biology, Harvard University, Cambridge, MA \\ 02138,
}

Department of Microbiology and Molecular Genetics, Harvard Medical School, Boston, MA 02115.

suzanne_walker@hms.harvard.edu; kahne@chemistry.harvard.edu

\section{Supporting Information-Spectra}




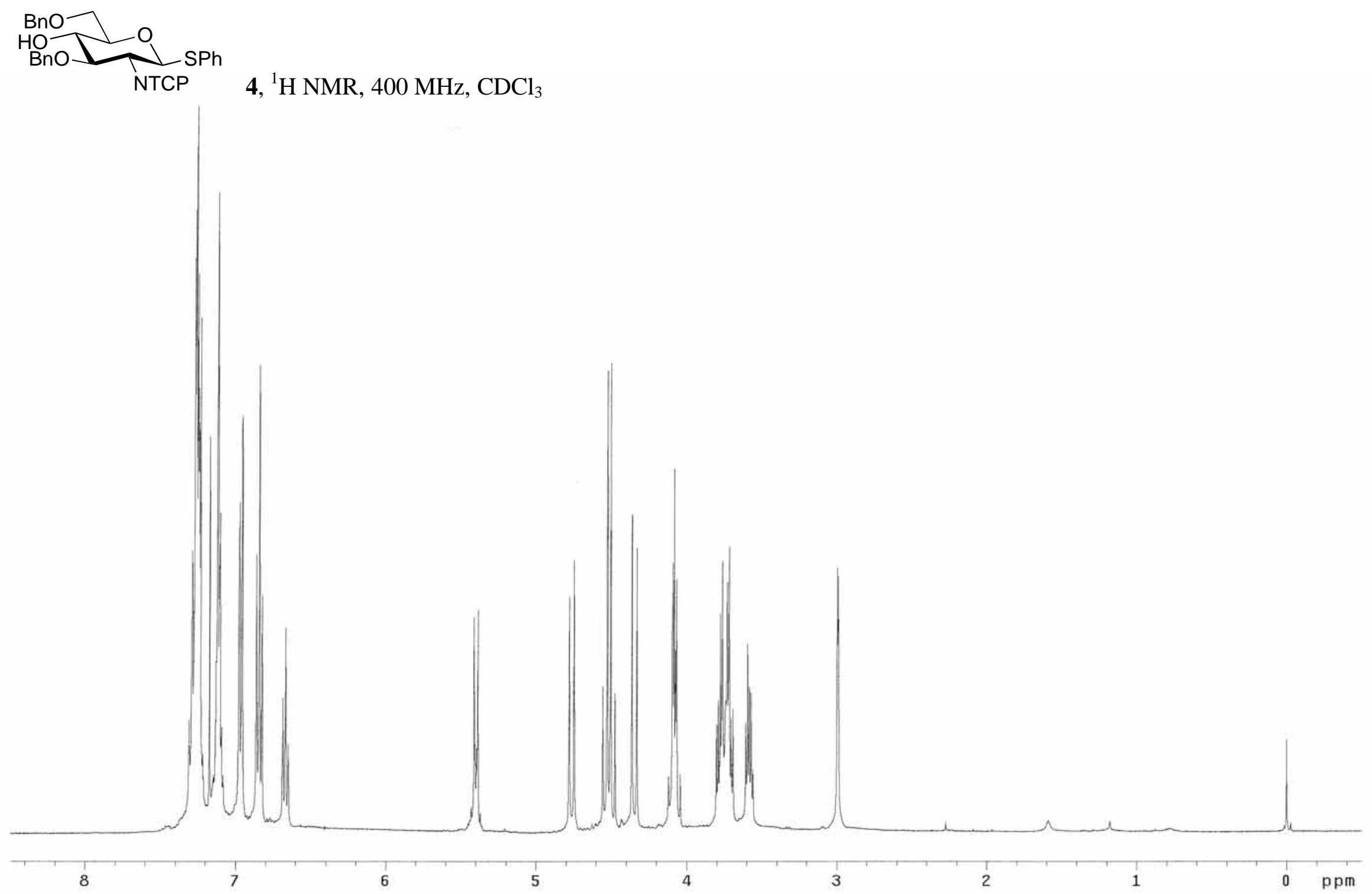

S2 2 
4, ${ }^{13} \mathrm{C}$ NMR, $100 \mathrm{MHz}, \mathrm{CDCl}_{3}$

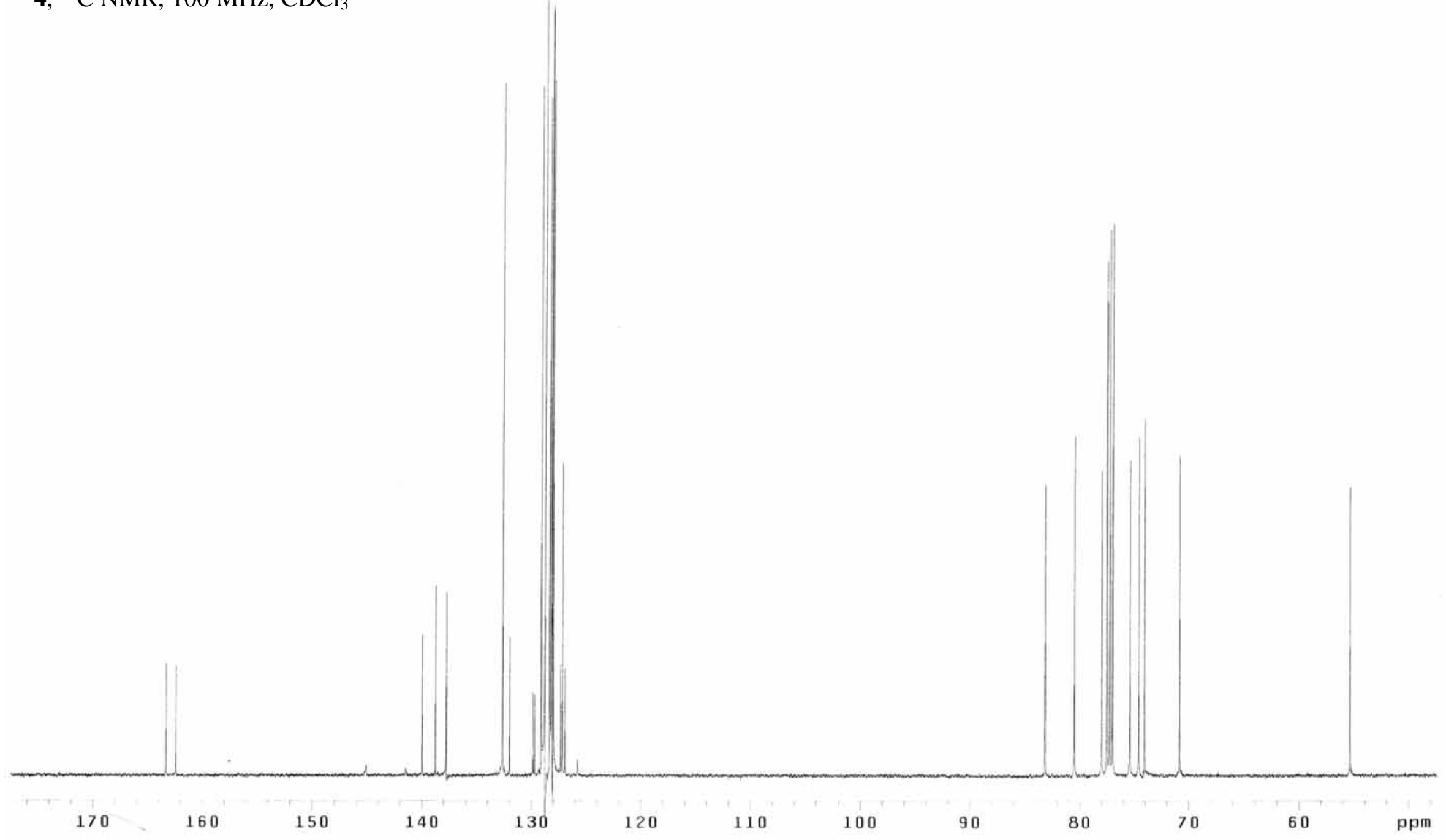



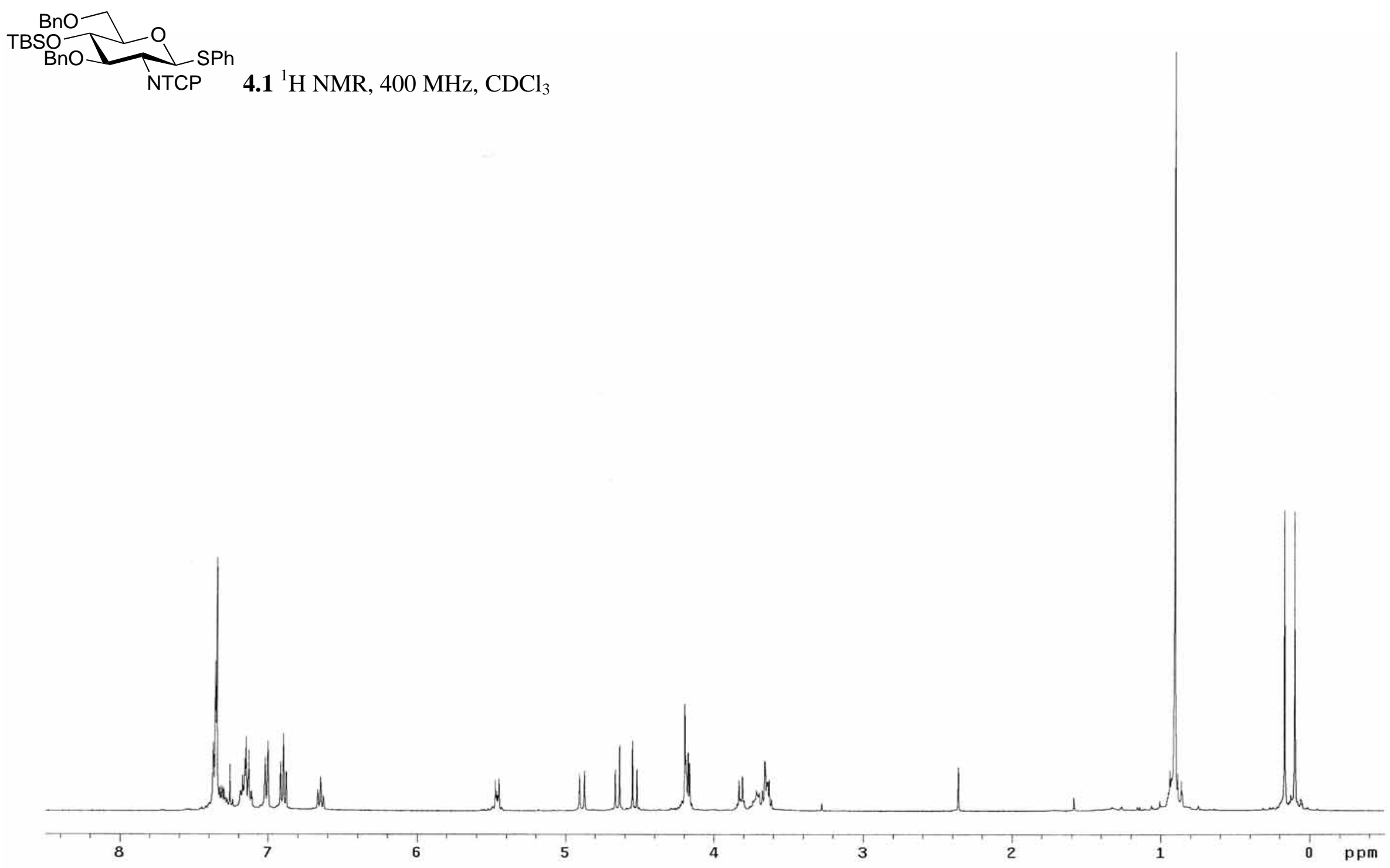

S2 4 
4.1, ${ }^{13} \mathrm{C}$ NMR, $100 \mathrm{MHz}, \mathrm{CDCl}_{3}$

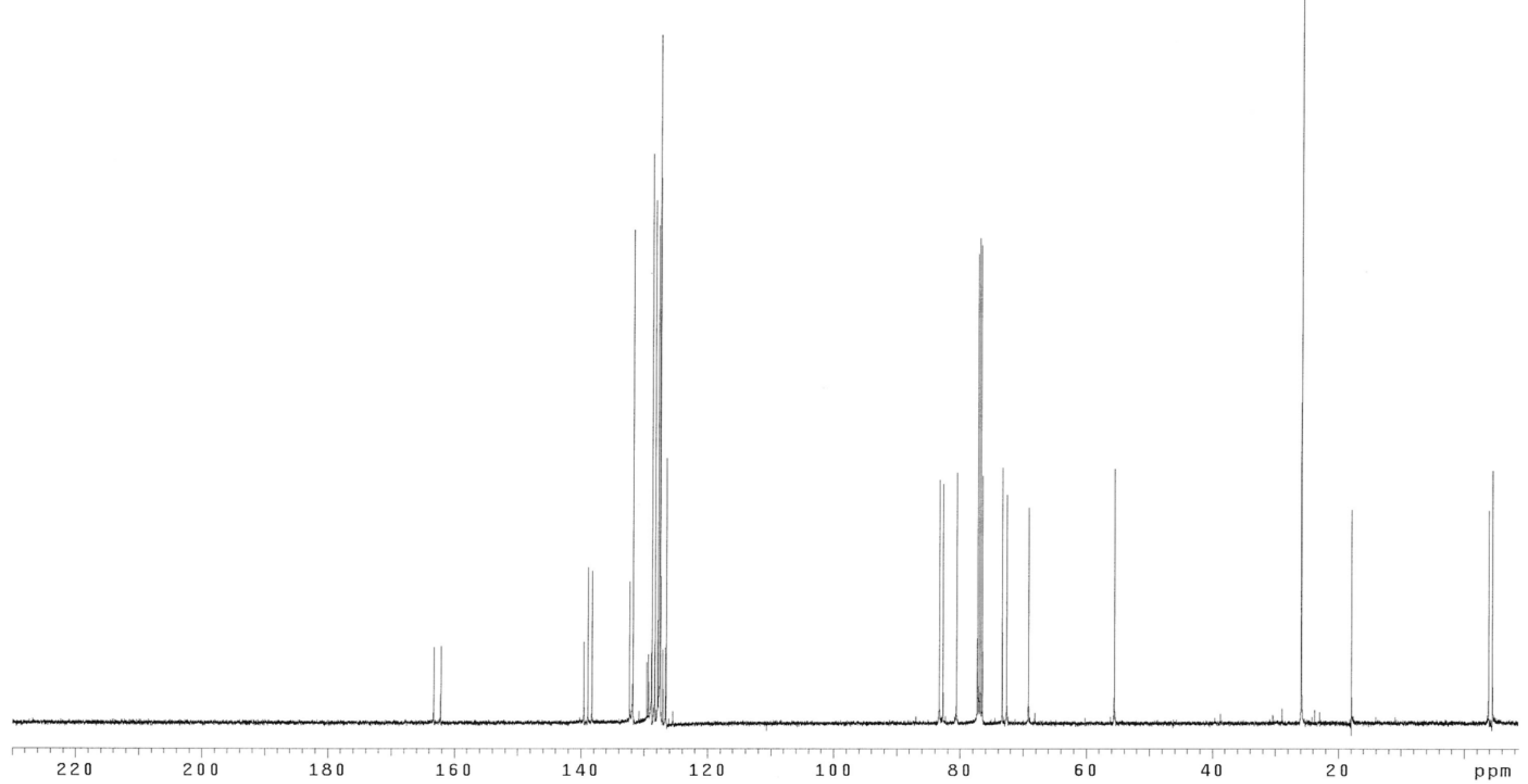



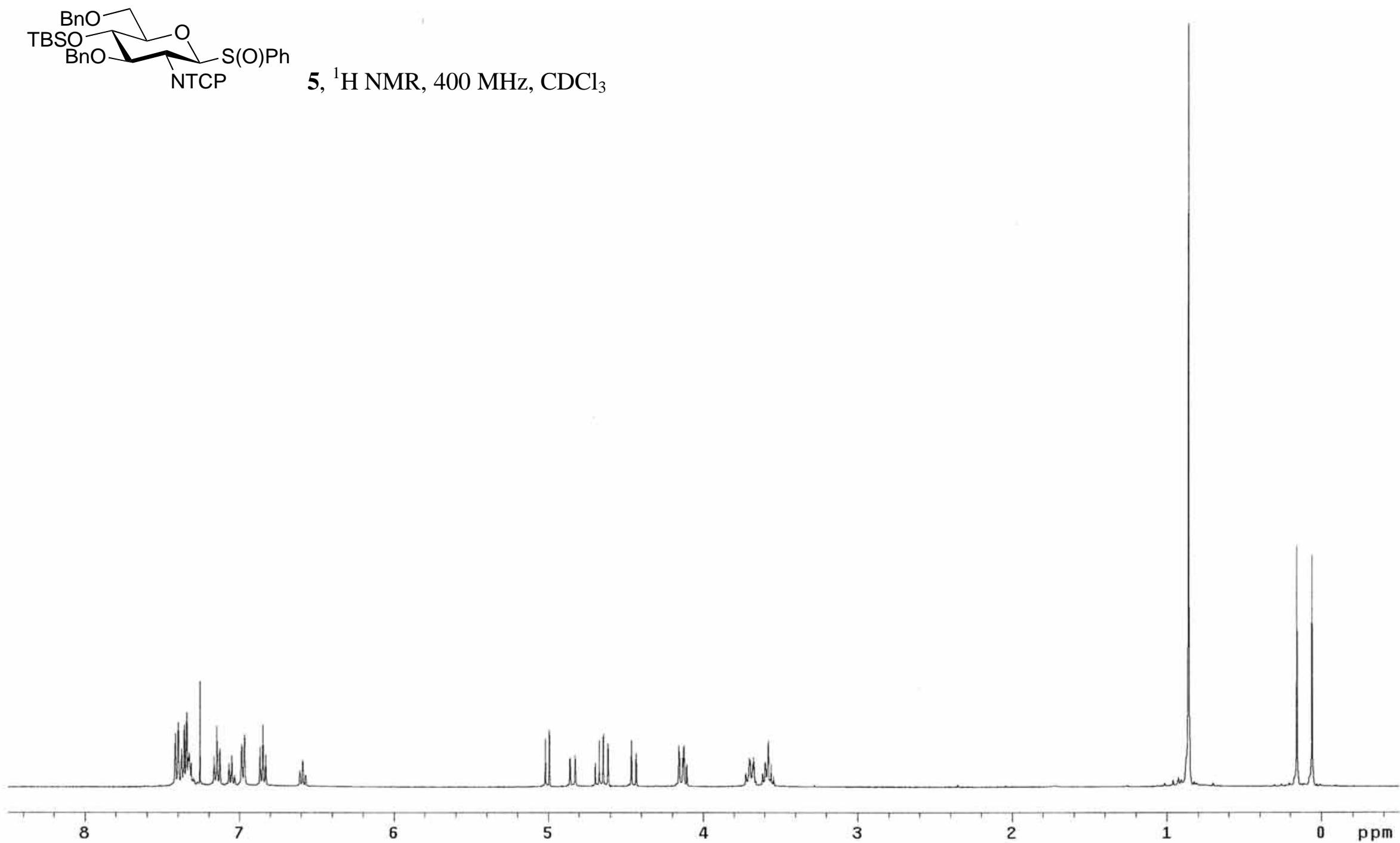
5, ${ }^{13} \mathrm{C} \mathrm{NMR,} 100 \mathrm{MHz}, \mathrm{CDCl}_{3}$

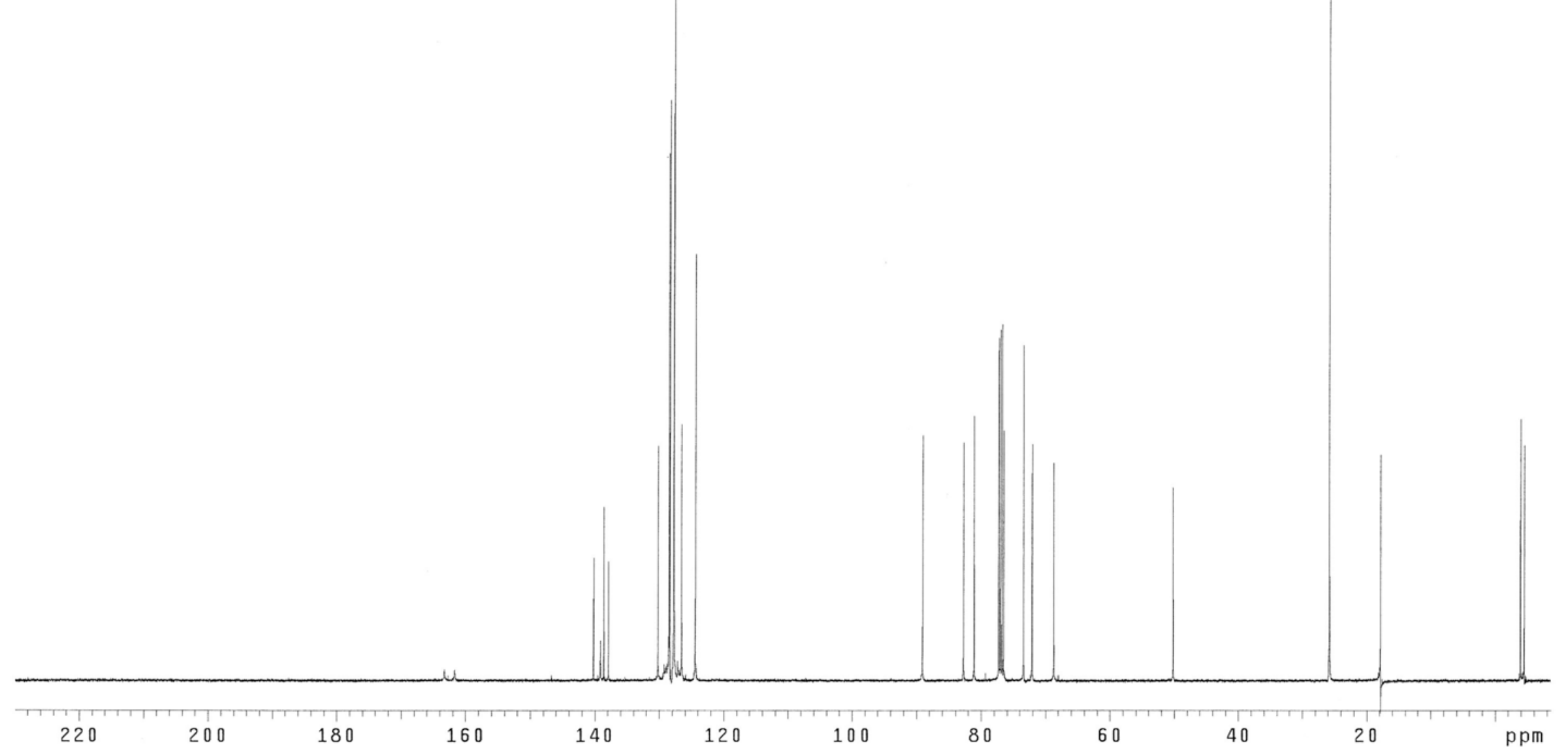




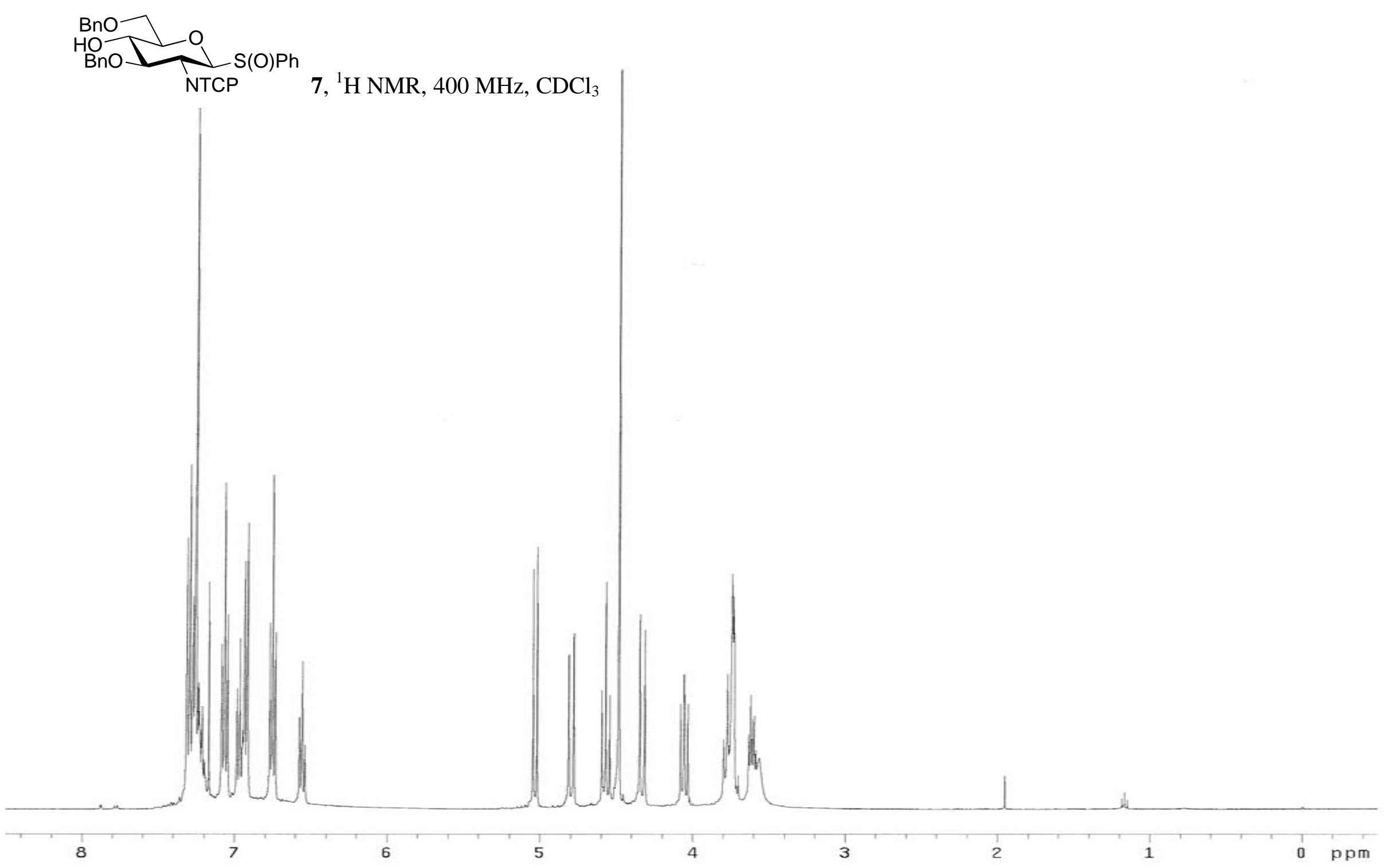


7, ${ }^{13} \mathrm{C} \mathrm{NMR}, 100 \mathrm{MHz}, \mathrm{CDCl}_{3}$

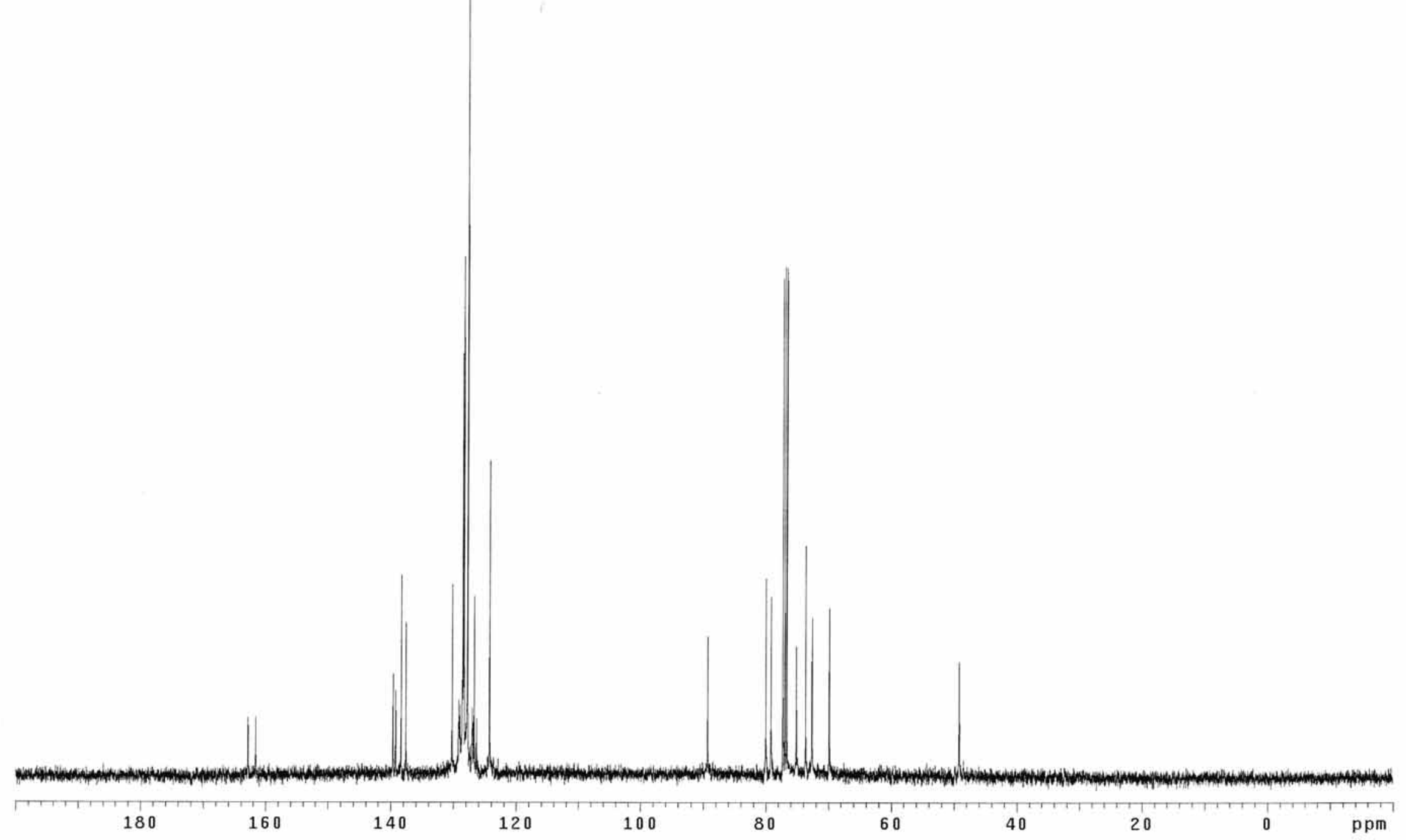



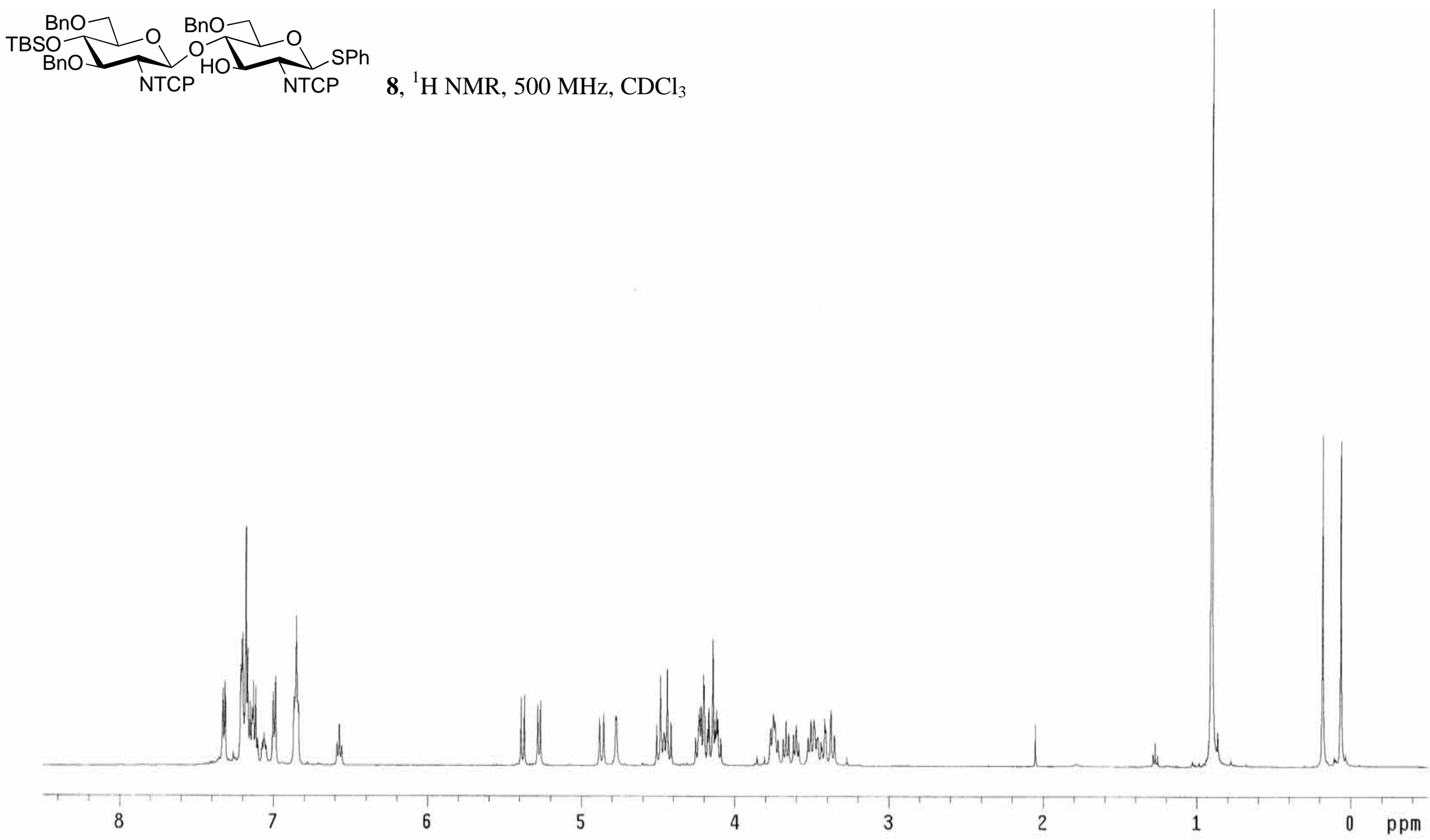

S2 10 
8, $\mathrm{COSY}$ (full), $500 \mathrm{MHz}, \mathrm{CDCl}_{3}$

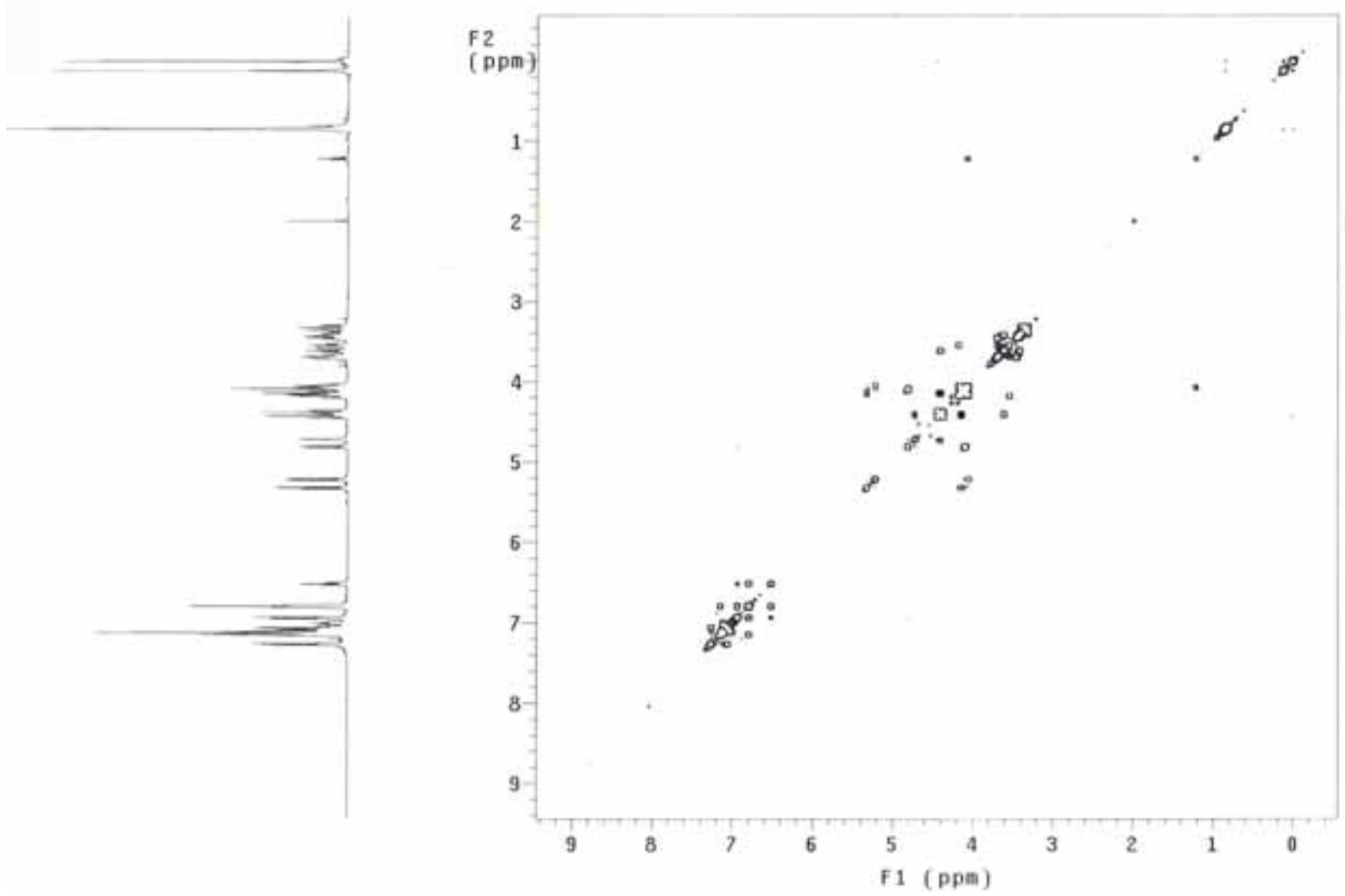

S2 11 
8, COSY (enlarged), $500 \mathrm{MHz}, \mathrm{CDCl}_{3}$
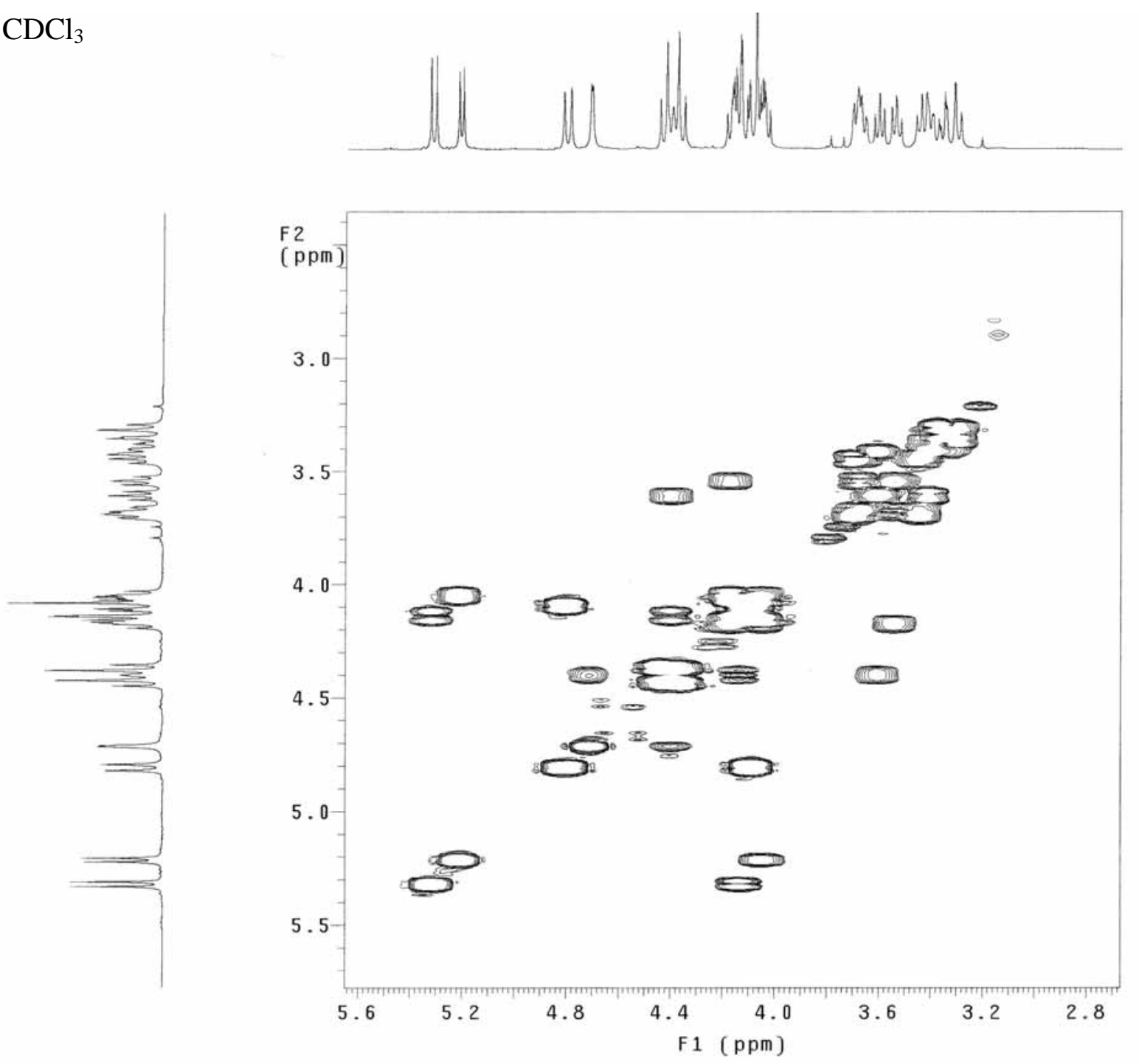
$\mathbf{8},{ }^{13} \mathrm{C}, 125 \mathrm{MHz}, \mathrm{CDCl}_{3}$

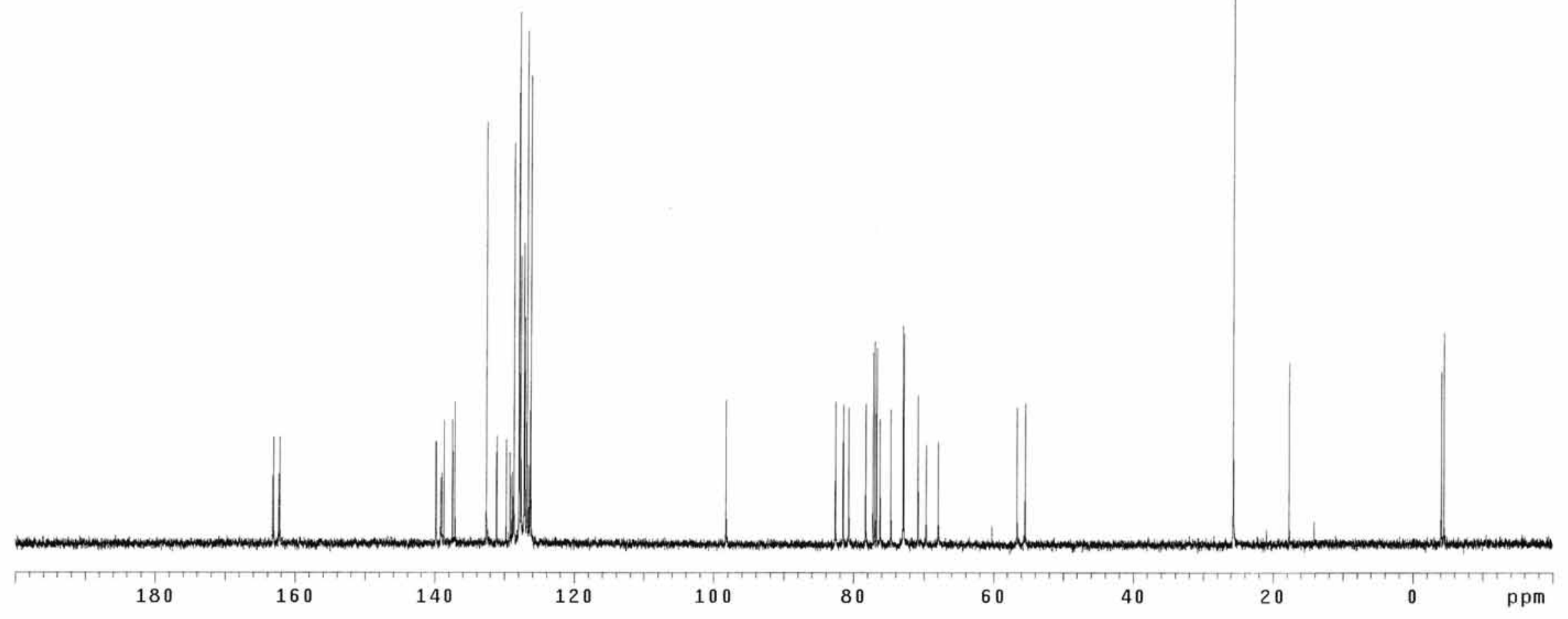


NTCP

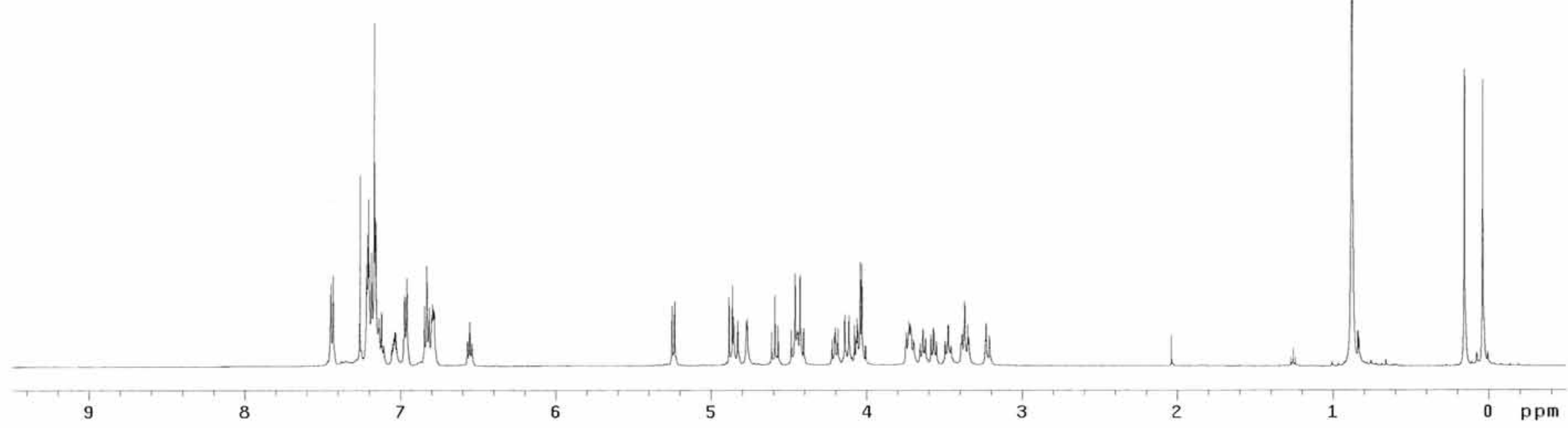


9, $\operatorname{COSY}\left(\right.$ full), $500 \mathrm{MHz}, \mathrm{CDCl}_{3}$

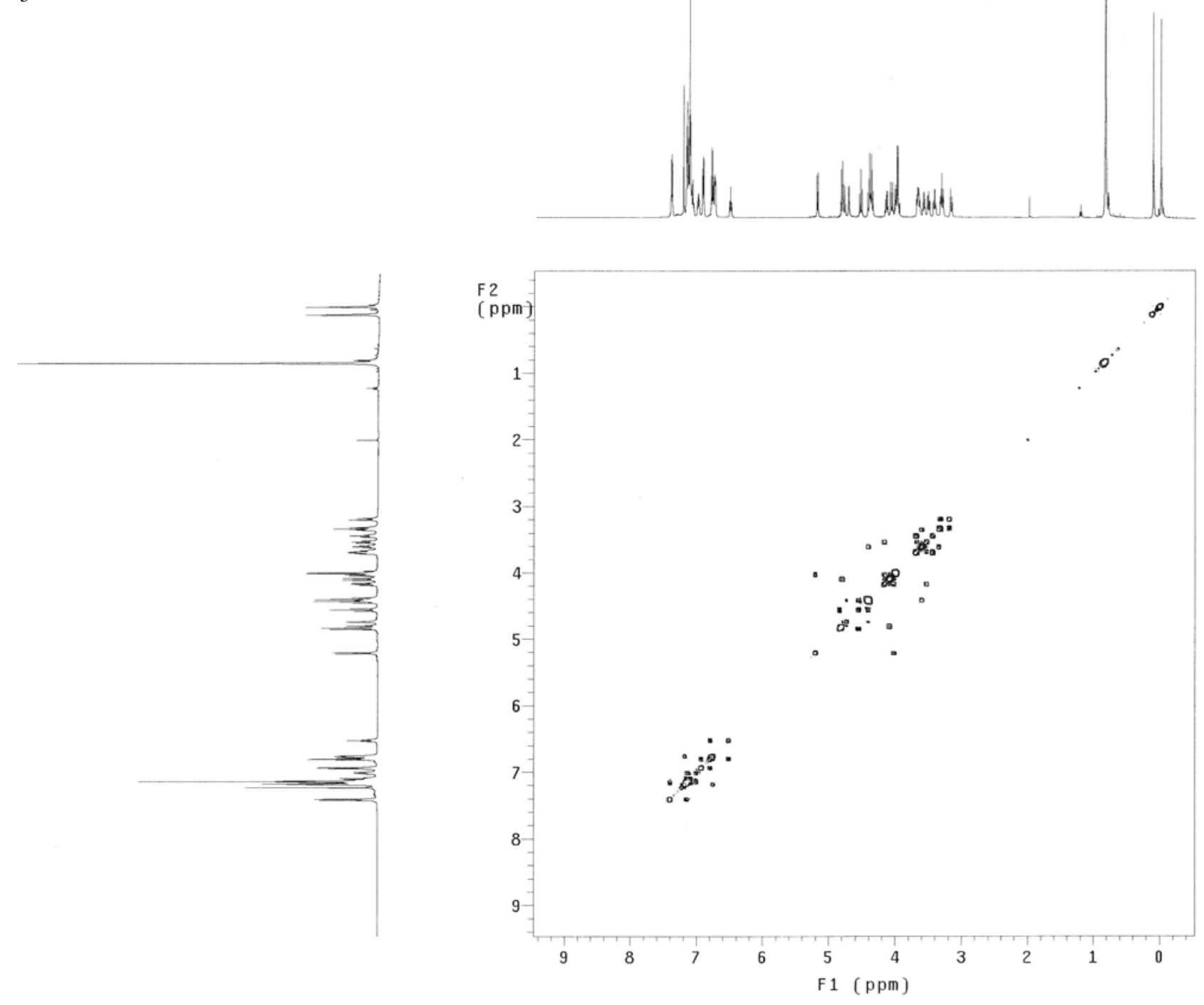


9, COSY(enlarged), $500 \mathrm{MHz}, \mathrm{CDCl}_{3}$

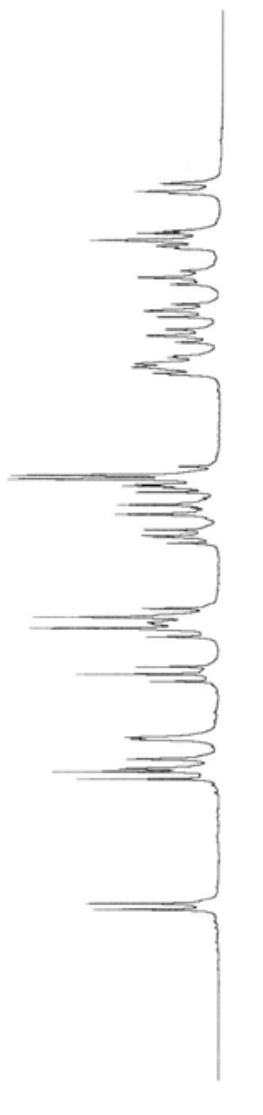

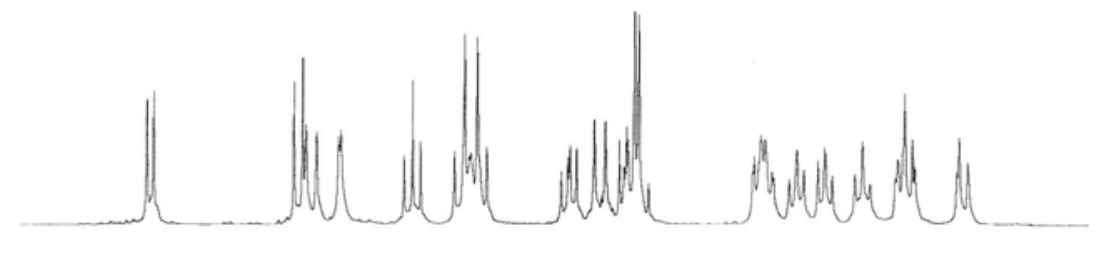

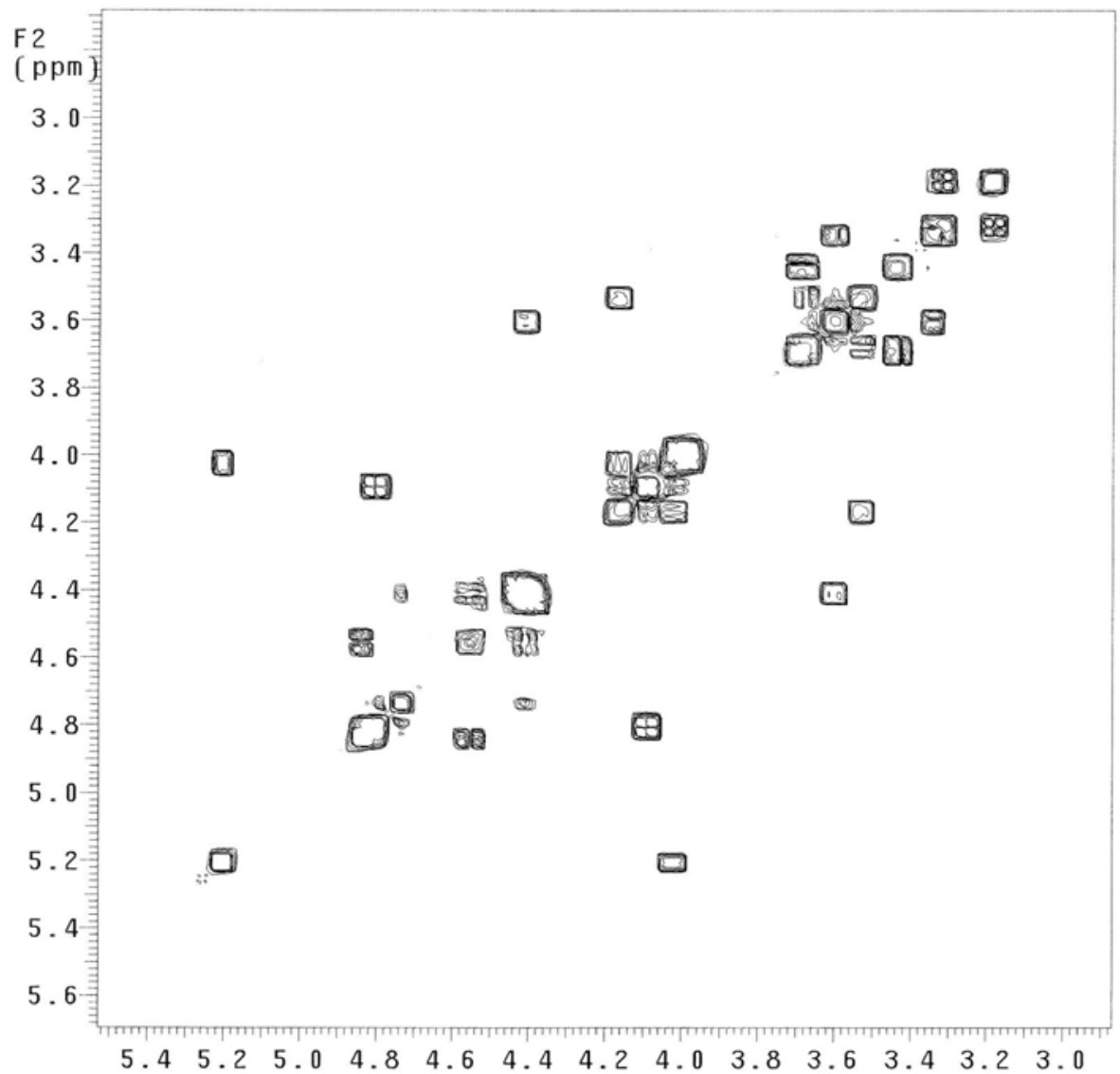

S2 16 
9, ${ }^{13} \mathrm{C}, 125 \mathrm{MHz}, \mathrm{CDCl}_{3}$

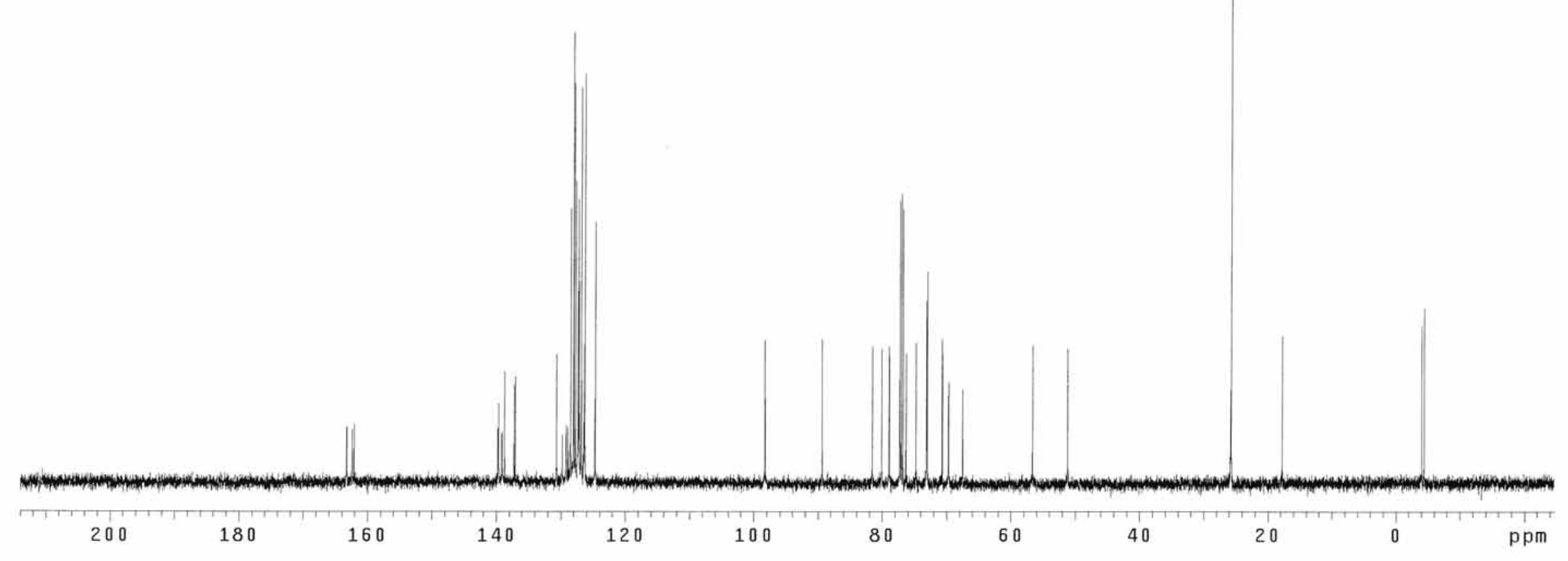




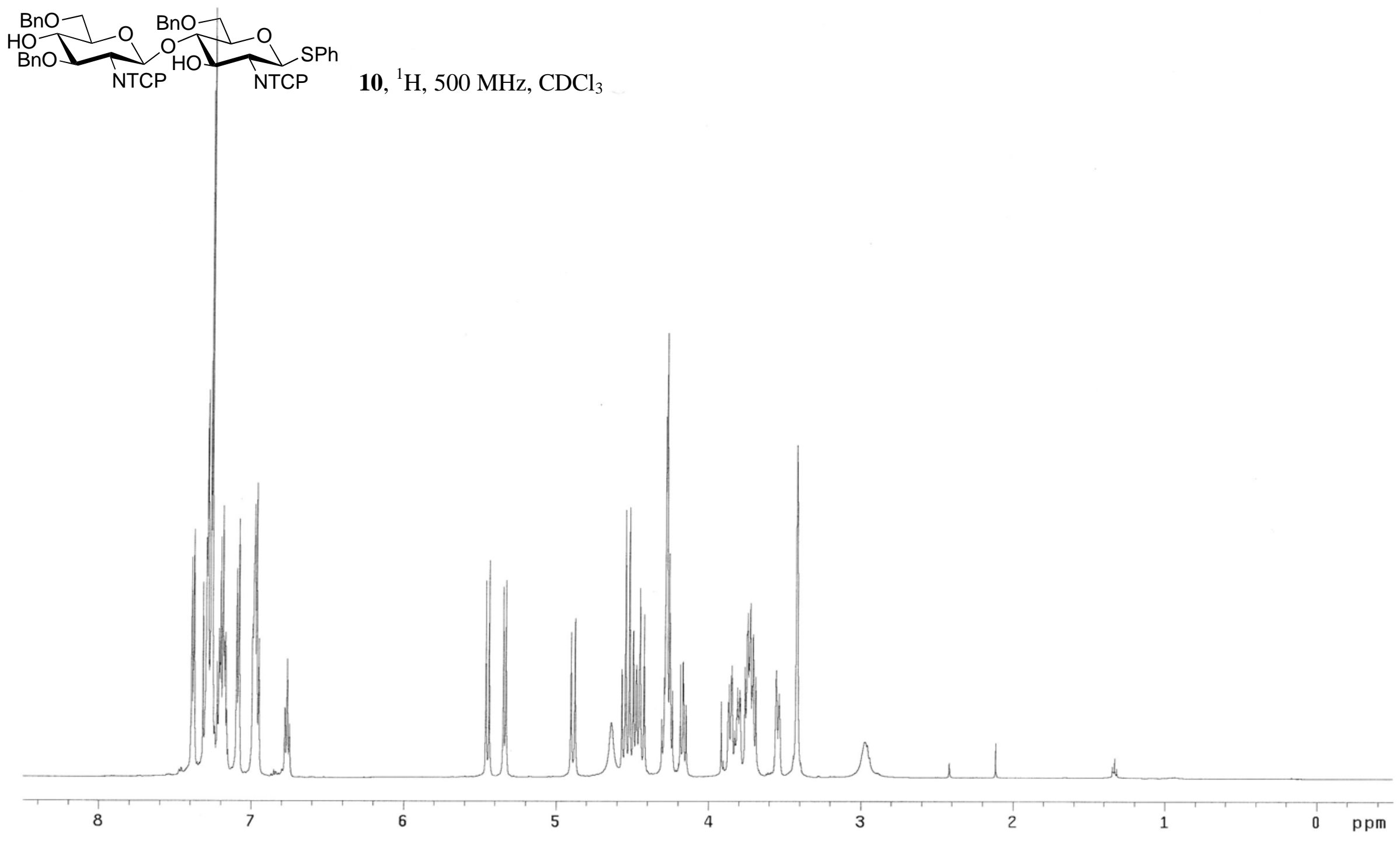


10, $\mathrm{COSY}, 500 \mathrm{MHz}, \mathrm{CDCl}_{3}$

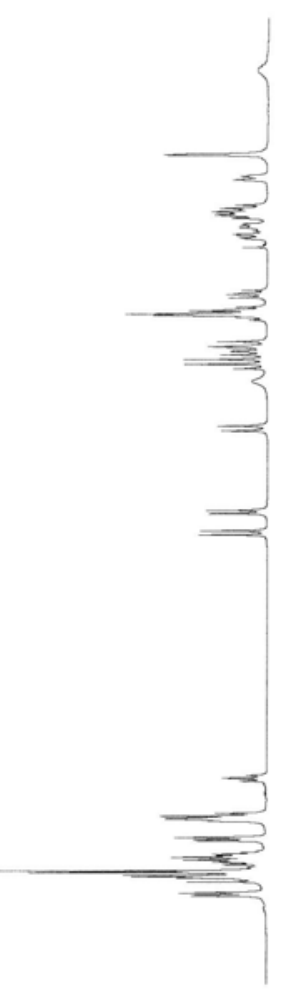

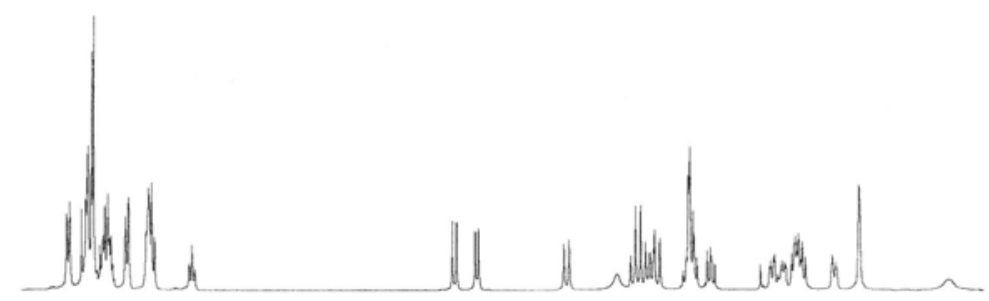

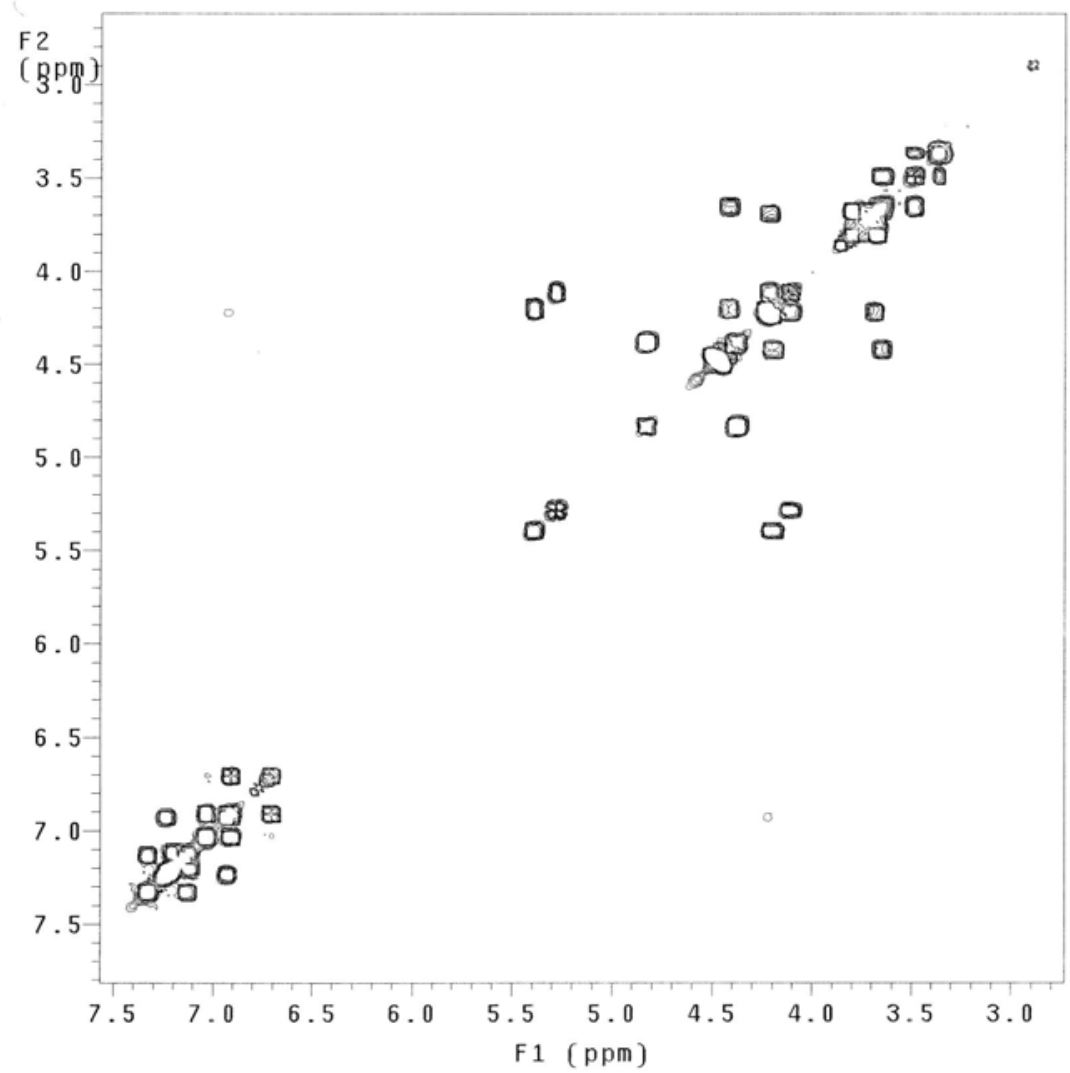


10, ${ }^{13} \mathrm{C}, 125 \mathrm{MHz}, \mathrm{CDCl}_{3}$

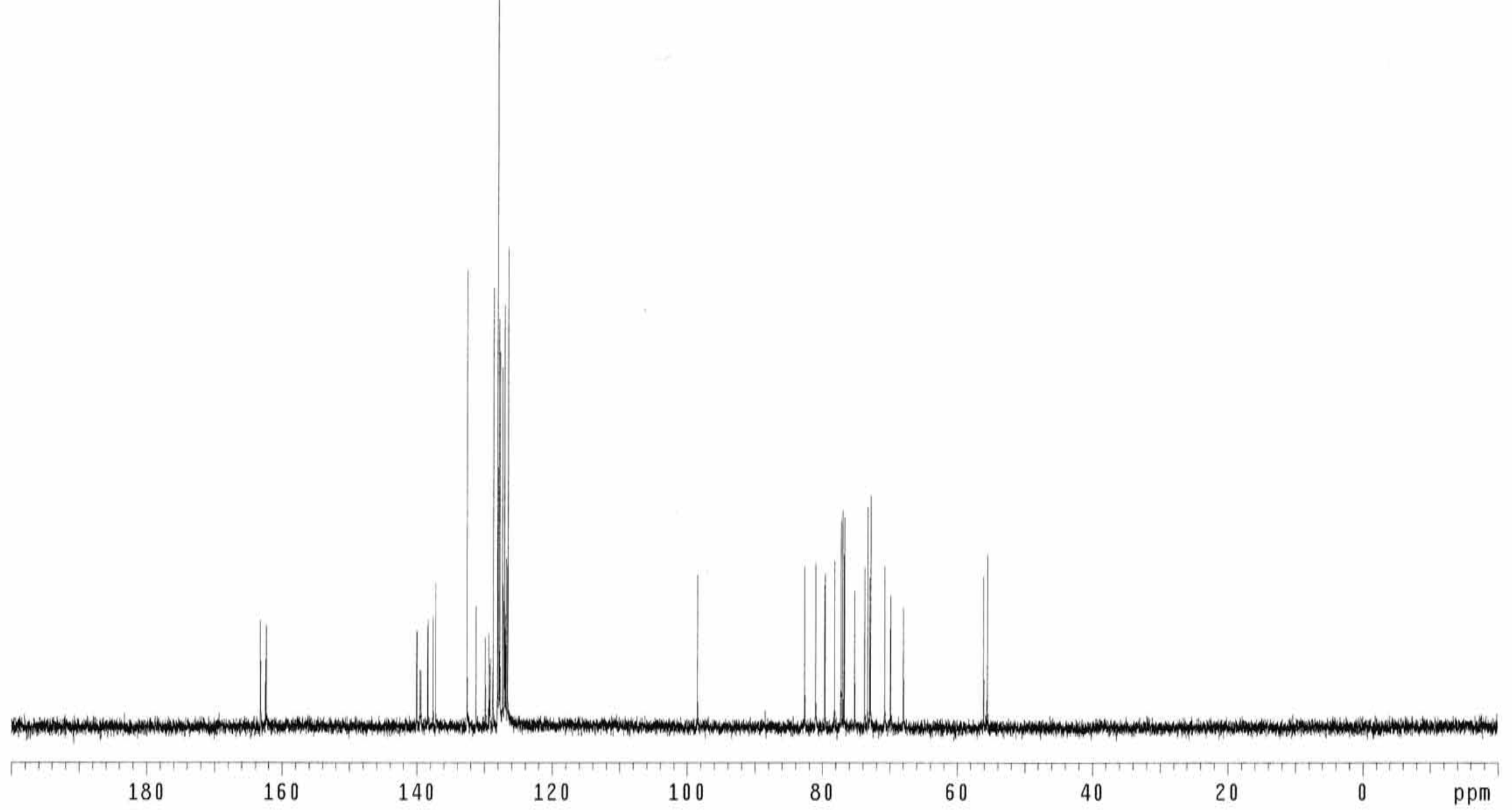




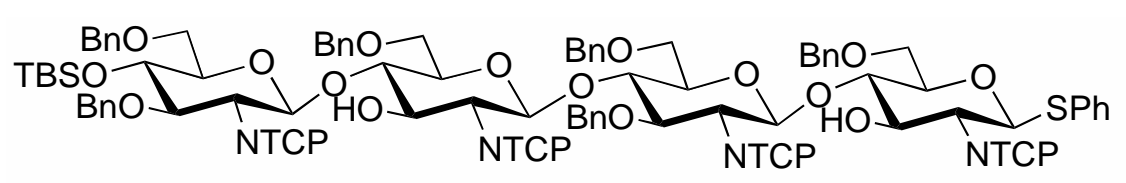

11, ${ }^{1} \mathrm{H}, 600 \mathrm{MHz}, \mathrm{CDCl}_{3}$

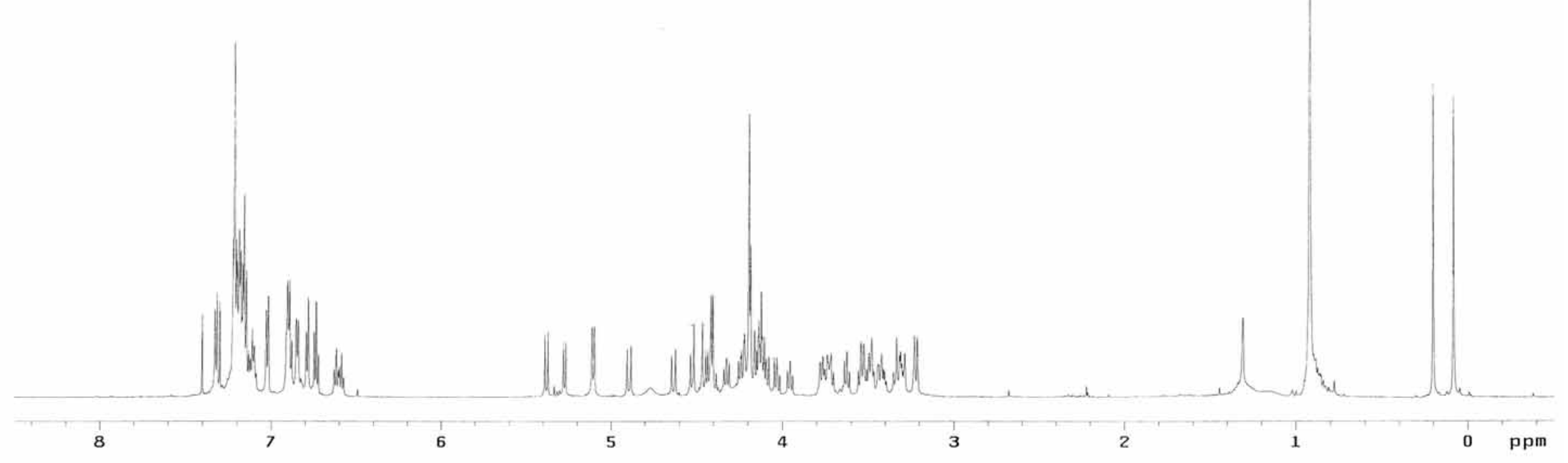


11, $\mathrm{COSY}$ (full), $600 \mathrm{MHz}, \mathrm{CDCl}_{3}$

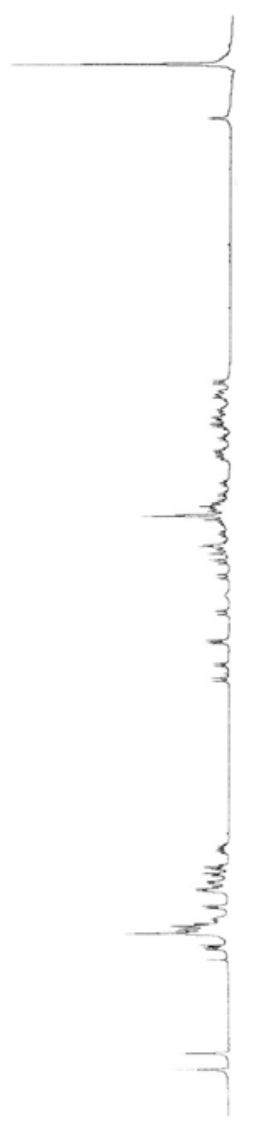

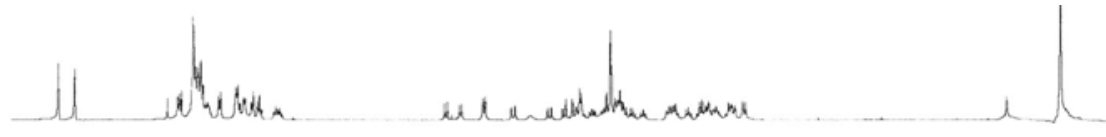

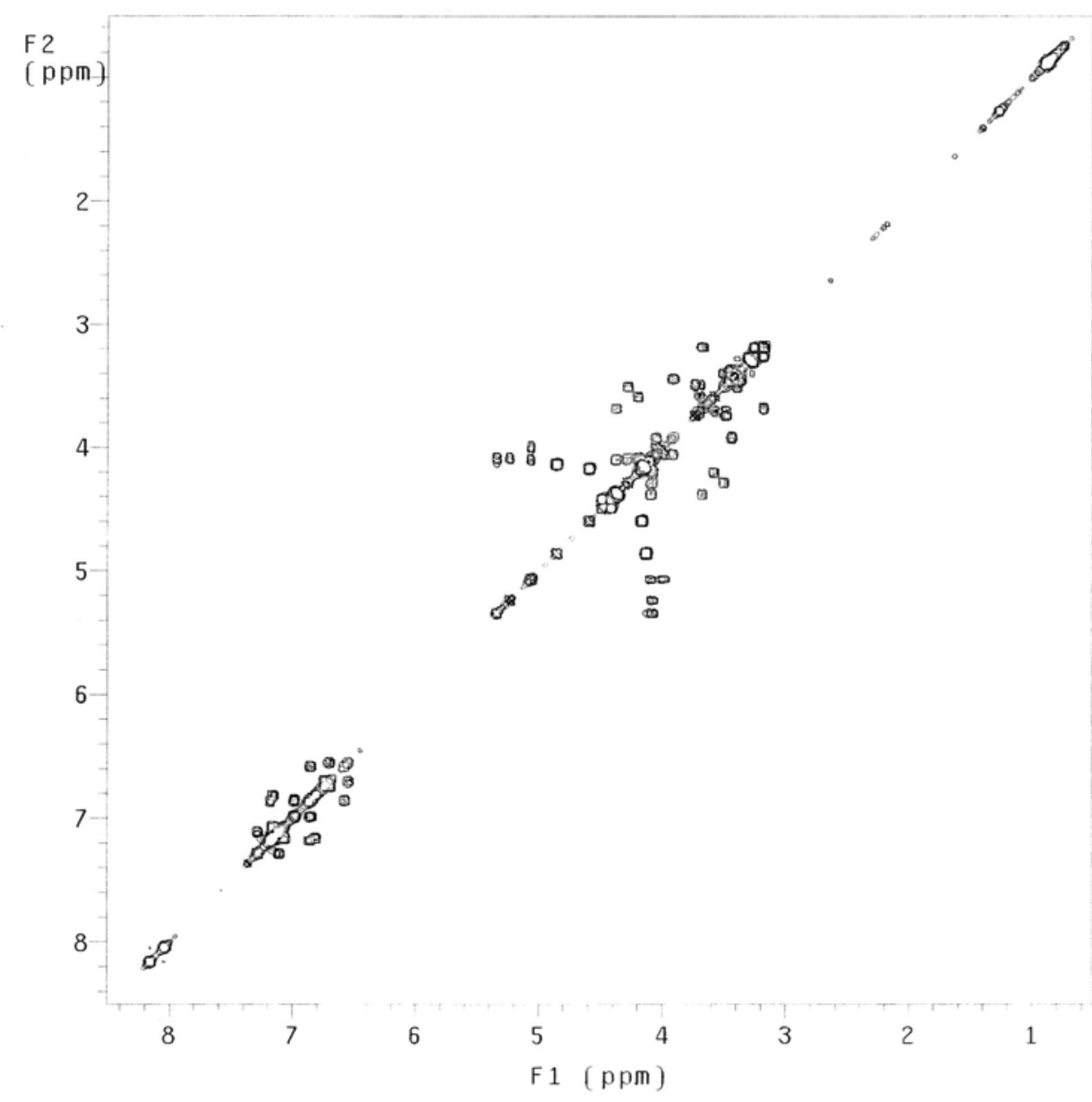

S2 22 
11, COSY(enlarged), $600 \mathrm{MHz}, \mathrm{CDCl}_{3}$
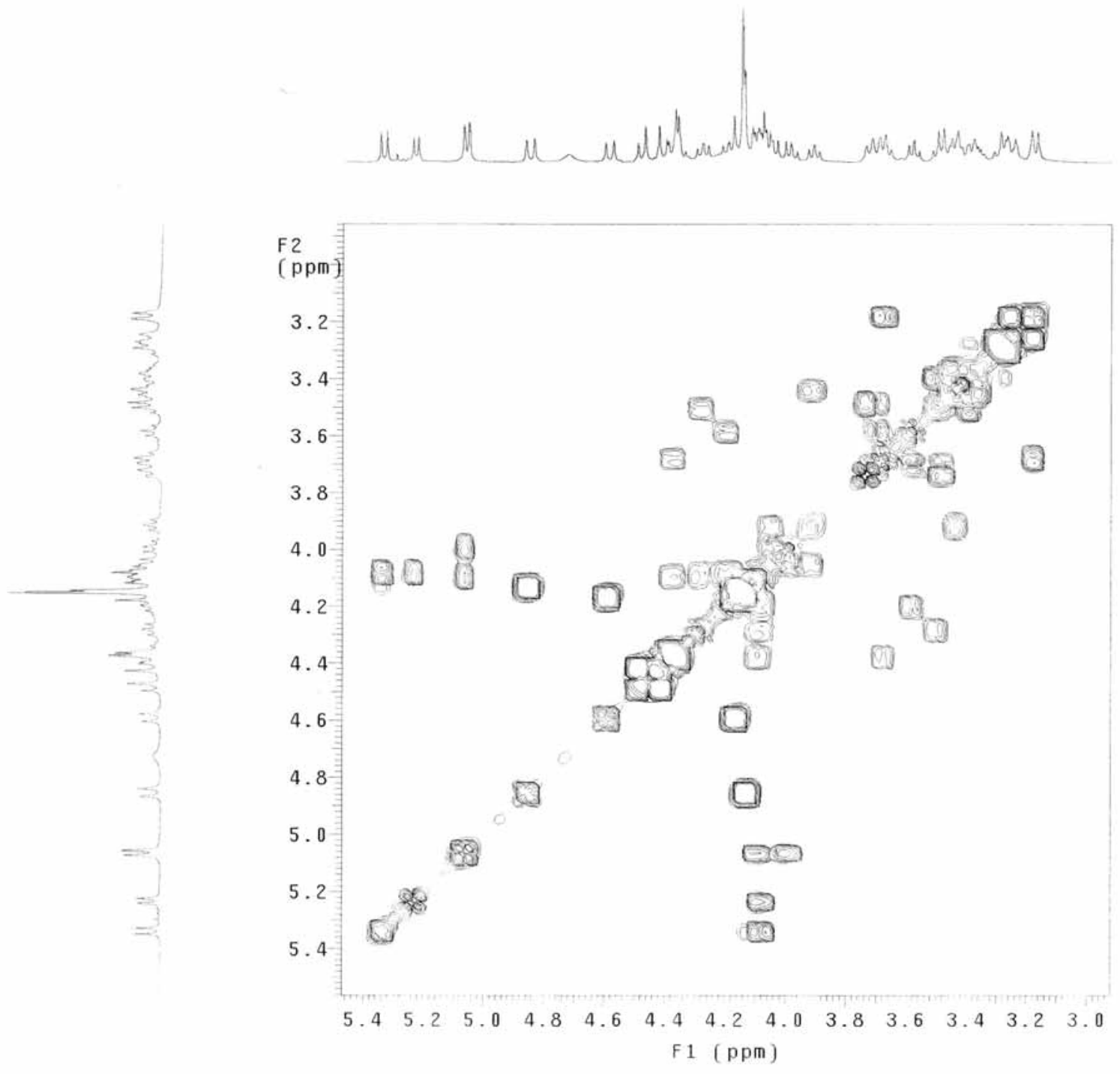
11, TOCSY, $600 \mathrm{MHz}, \mathrm{CDCl}_{3}$

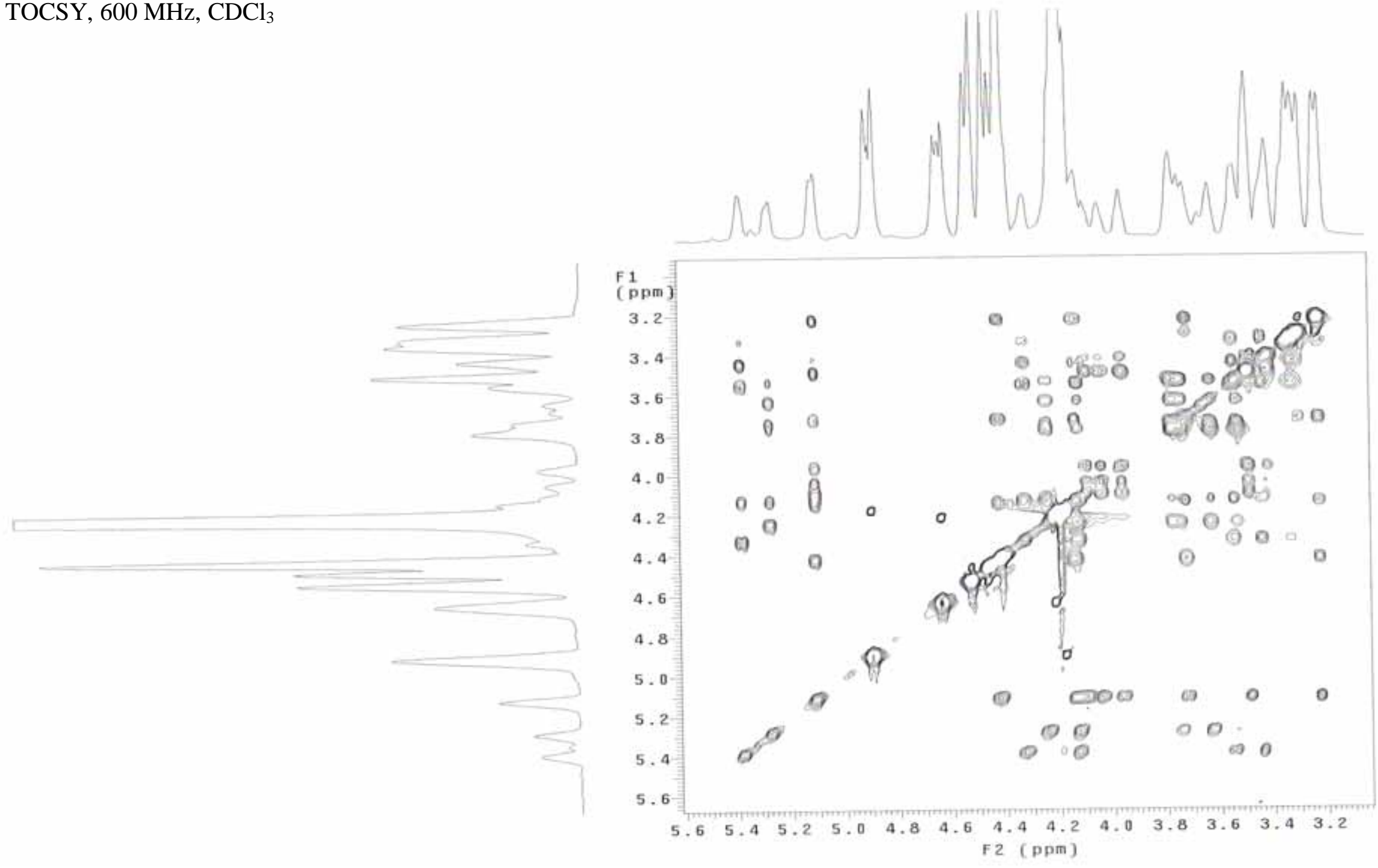


11, ${ }^{13} \mathrm{C}, 125 \mathrm{MHz}, \mathrm{CDCl}_{3}$

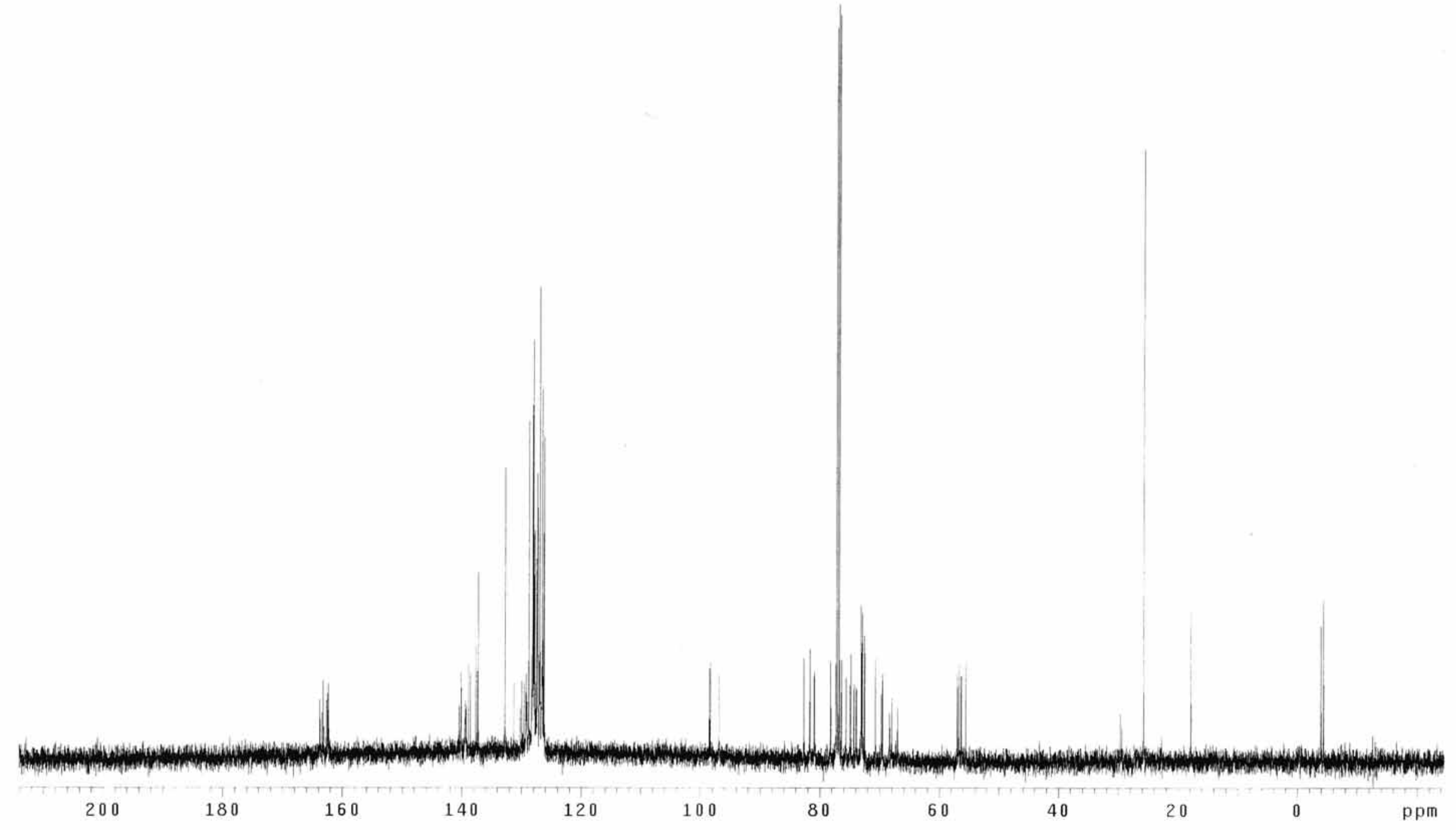




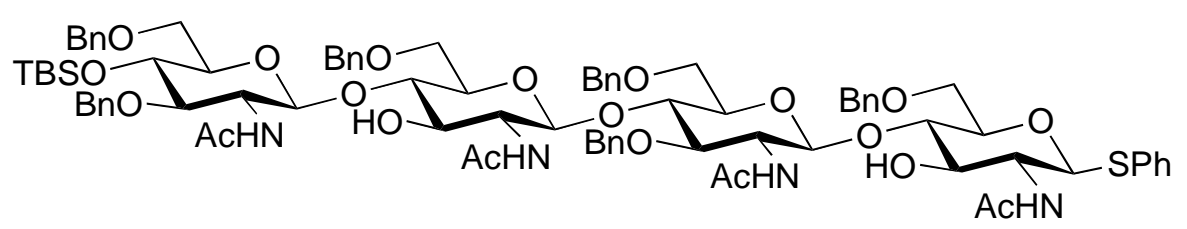

12, ${ }^{1} \mathrm{H}, 600 \mathrm{MHz}, \mathrm{CD}_{3} \mathrm{OD}$

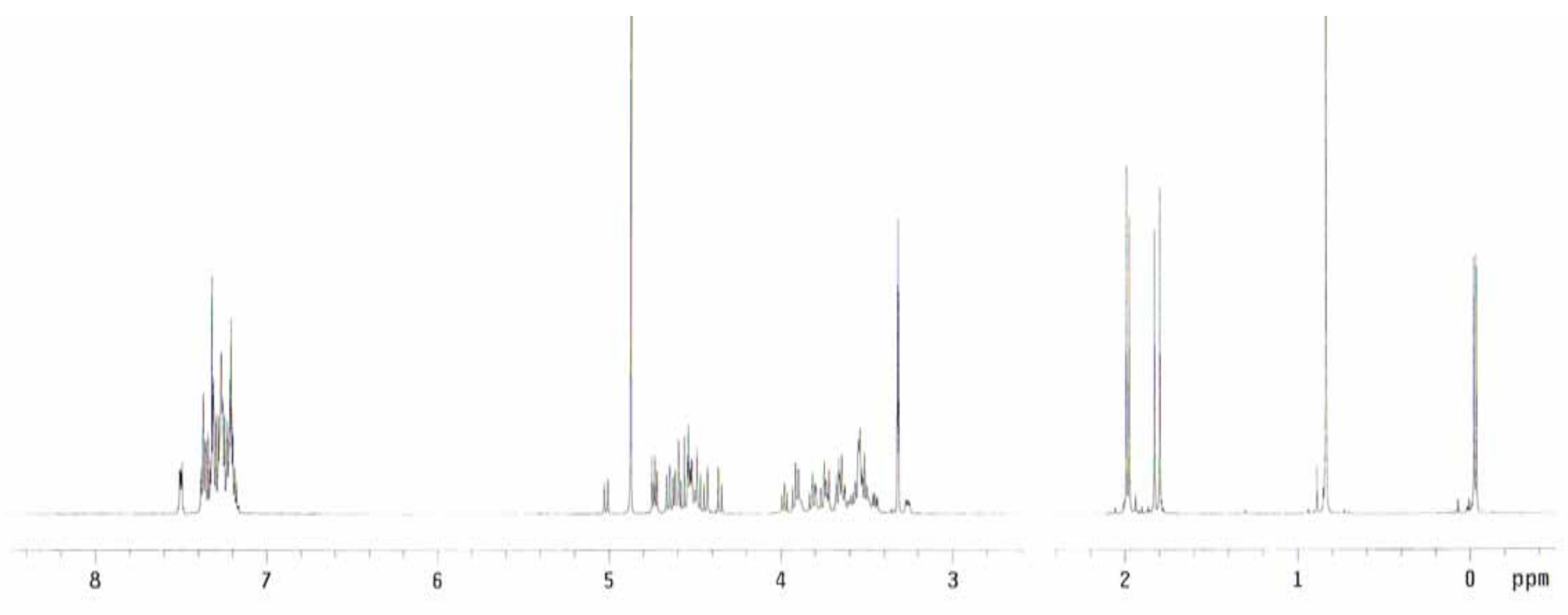


12, $\mathrm{COSY}, 600 \mathrm{MHz}, \mathrm{CD}_{3} \mathrm{OD}$
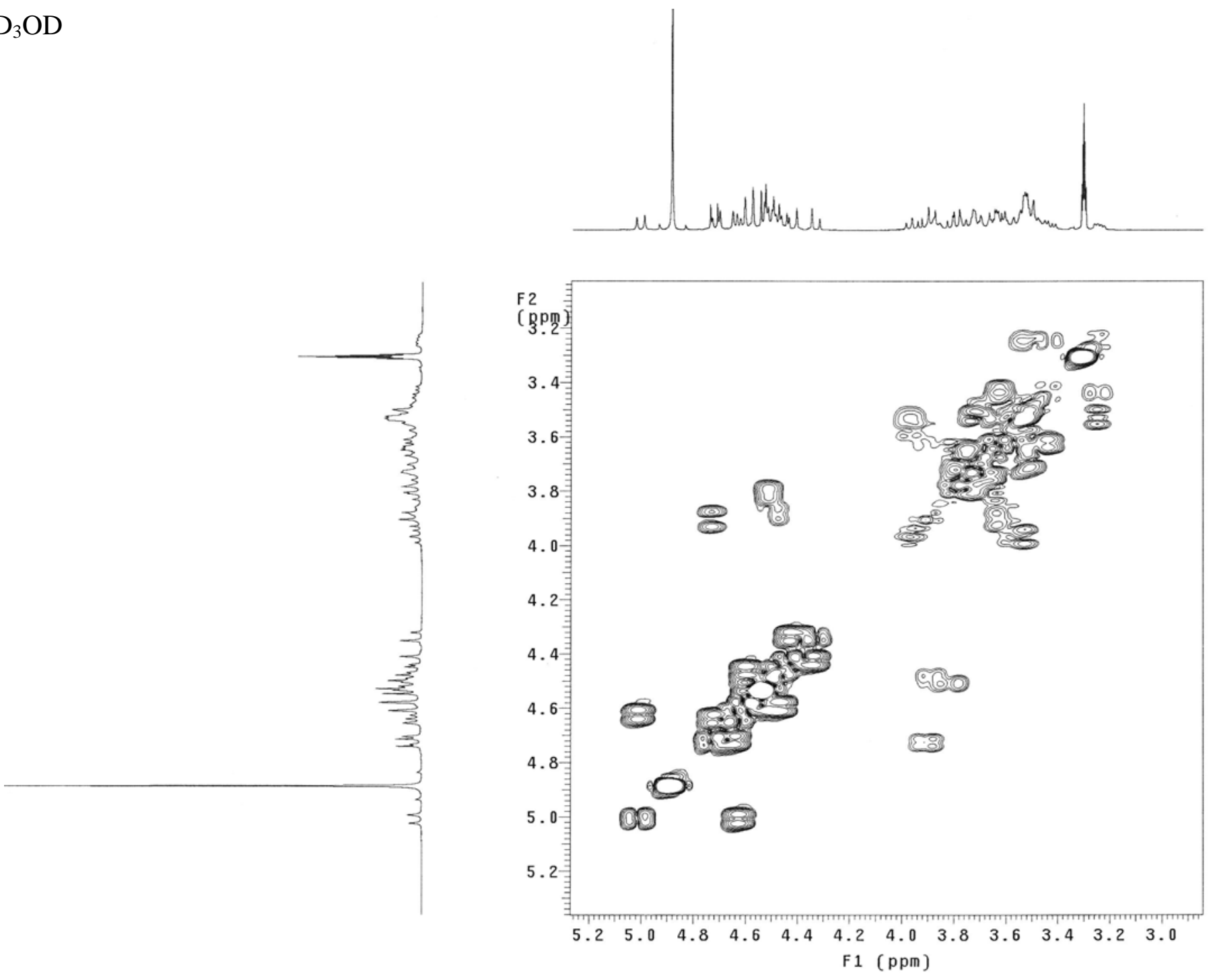
12, ${ }^{13} \mathrm{C}, 100 \mathrm{MHz}, \mathrm{CD}_{3} \mathrm{OD}$

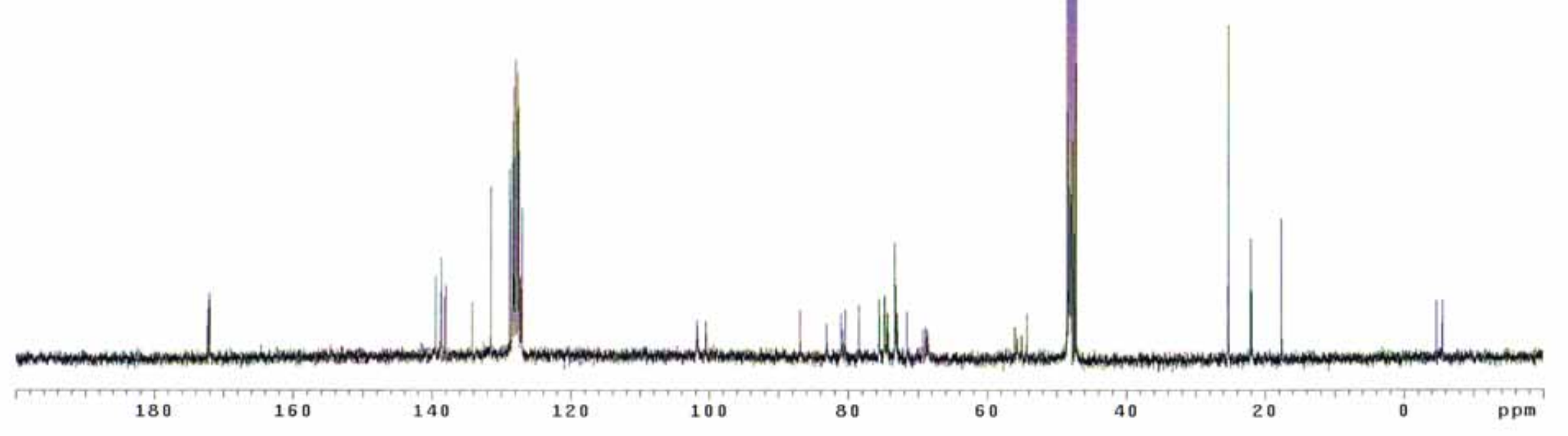




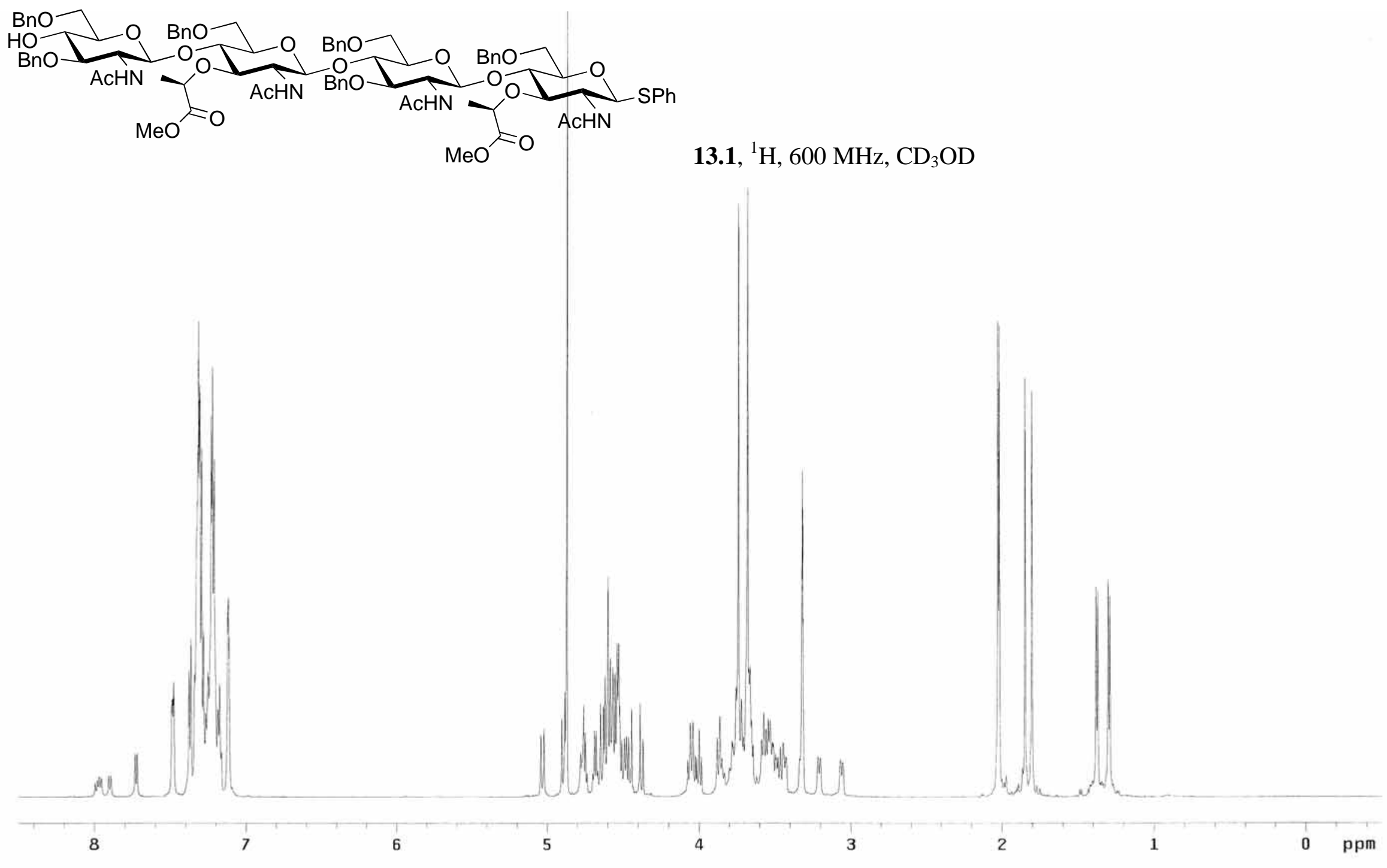

S2 29 
13.1, COSY(full), $600 \mathrm{MHz}, \mathrm{CD}_{3} \mathrm{OD}$

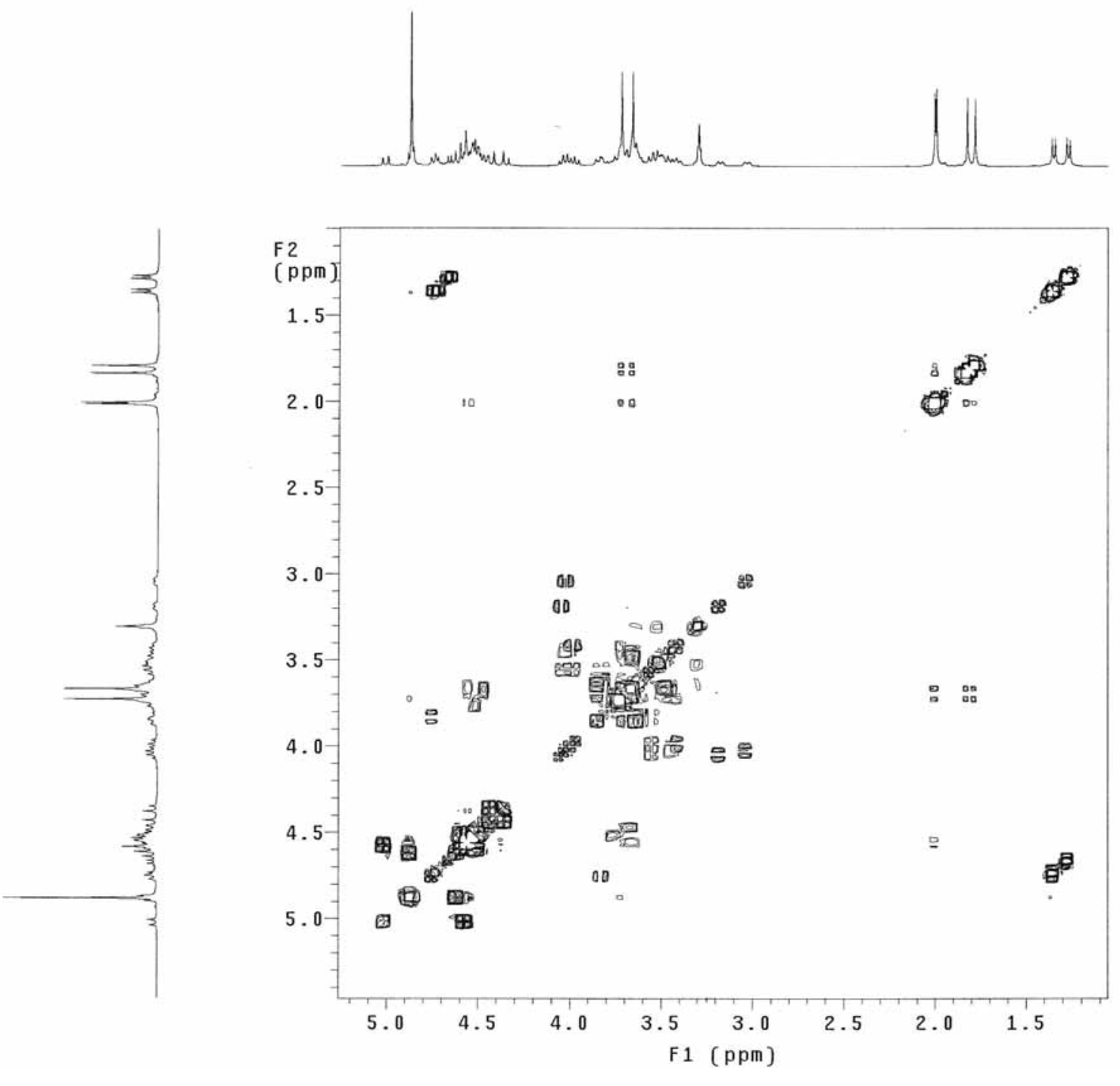


13.1, COSY(enlarged), $600 \mathrm{MHz}, \mathrm{CD}_{3} \mathrm{OD}$

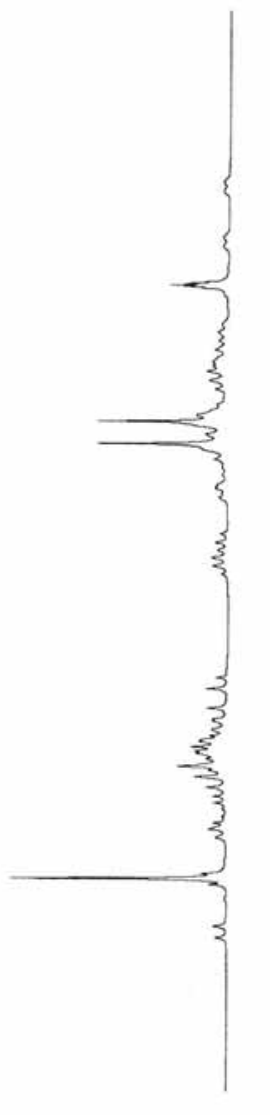

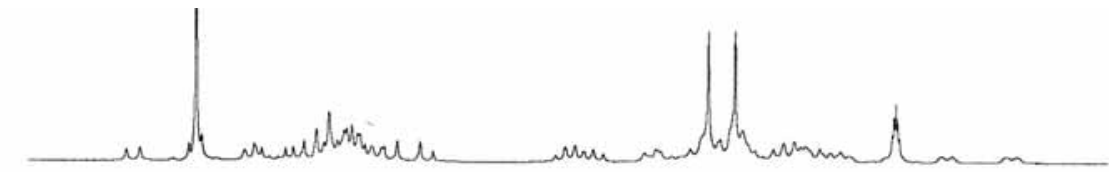

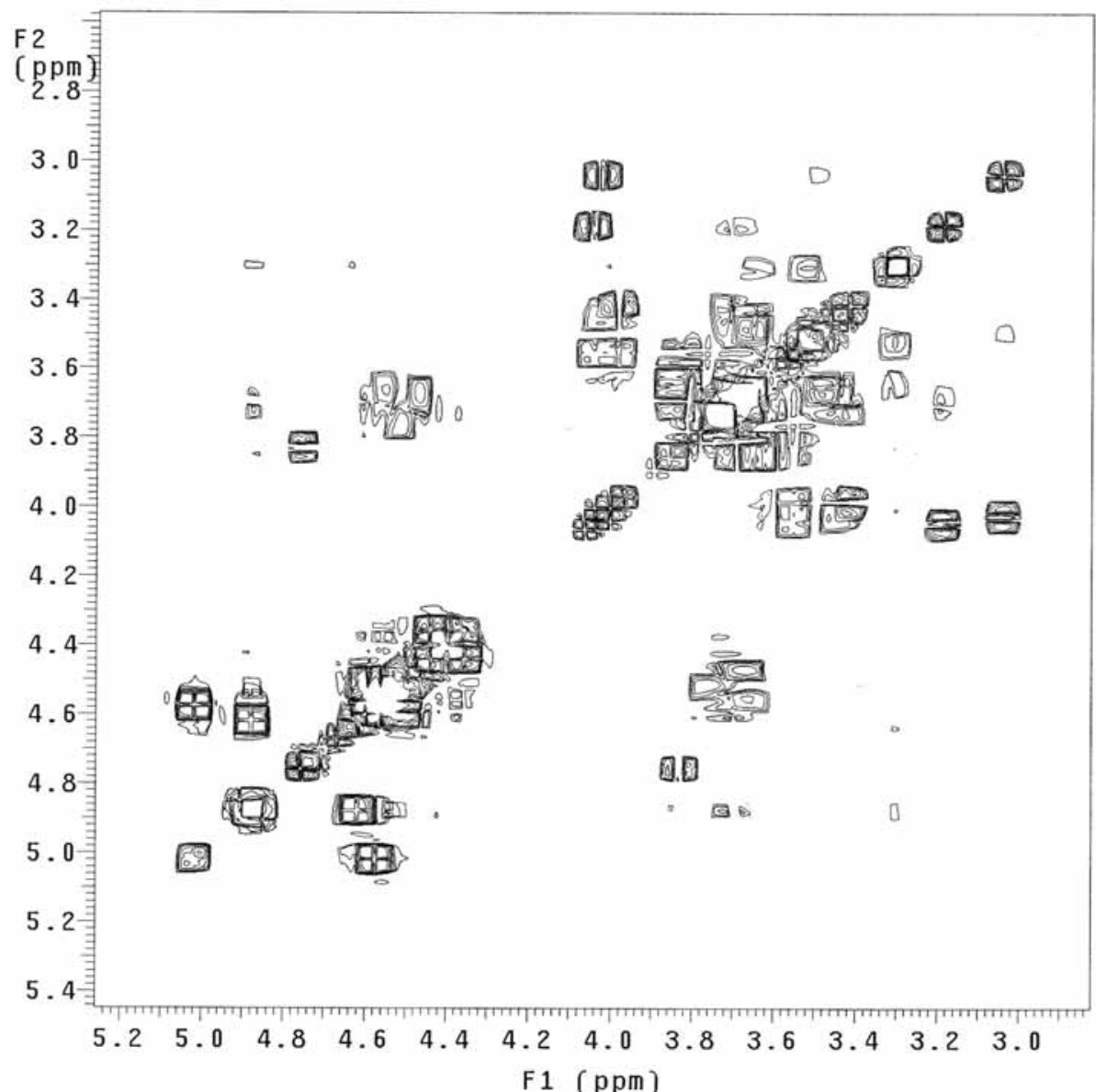

S2 31 
13.1, ${ }^{13} \mathrm{C}, 100 \mathrm{MHz}, \mathrm{CD}_{3} \mathrm{OD}$

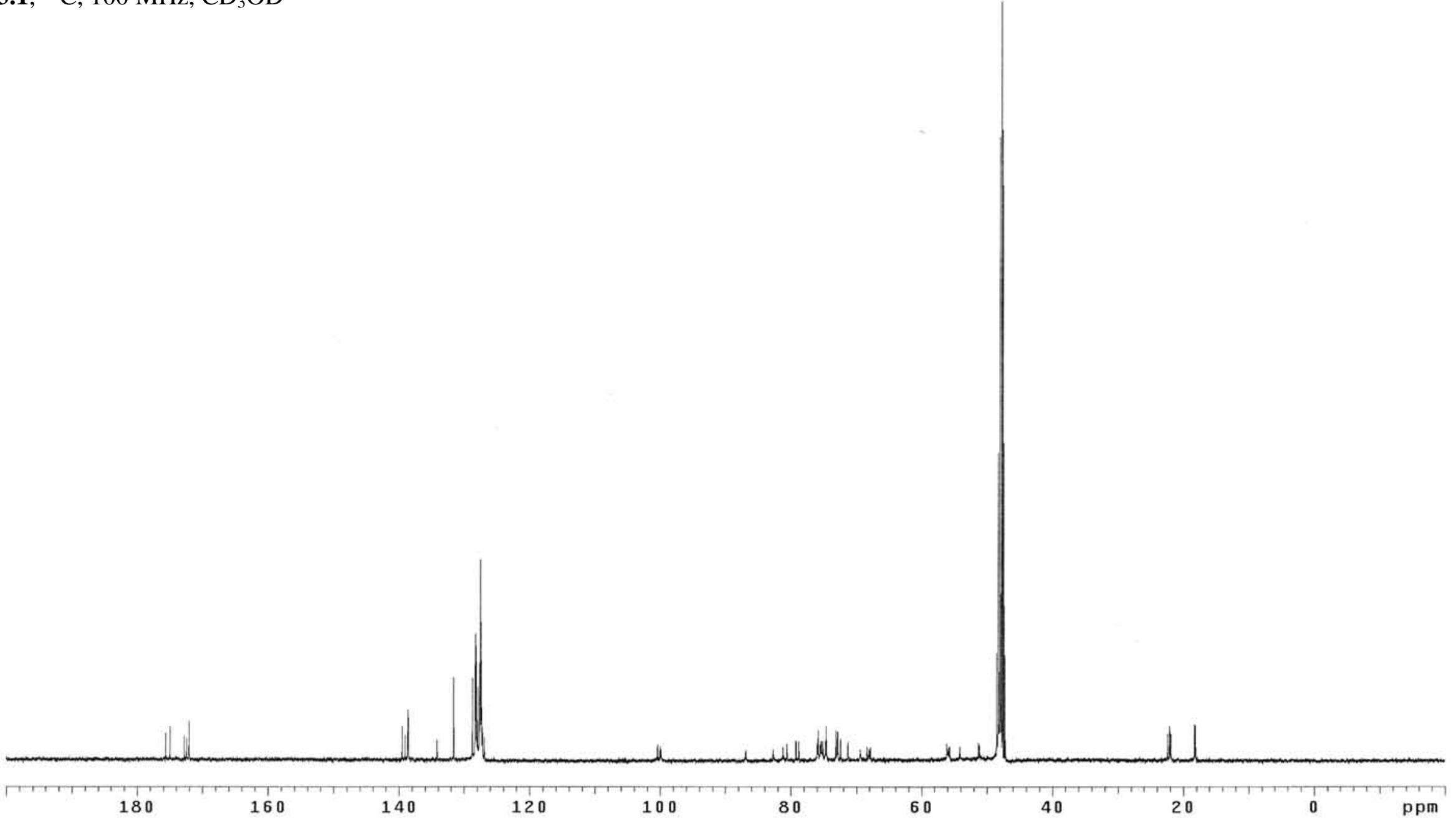




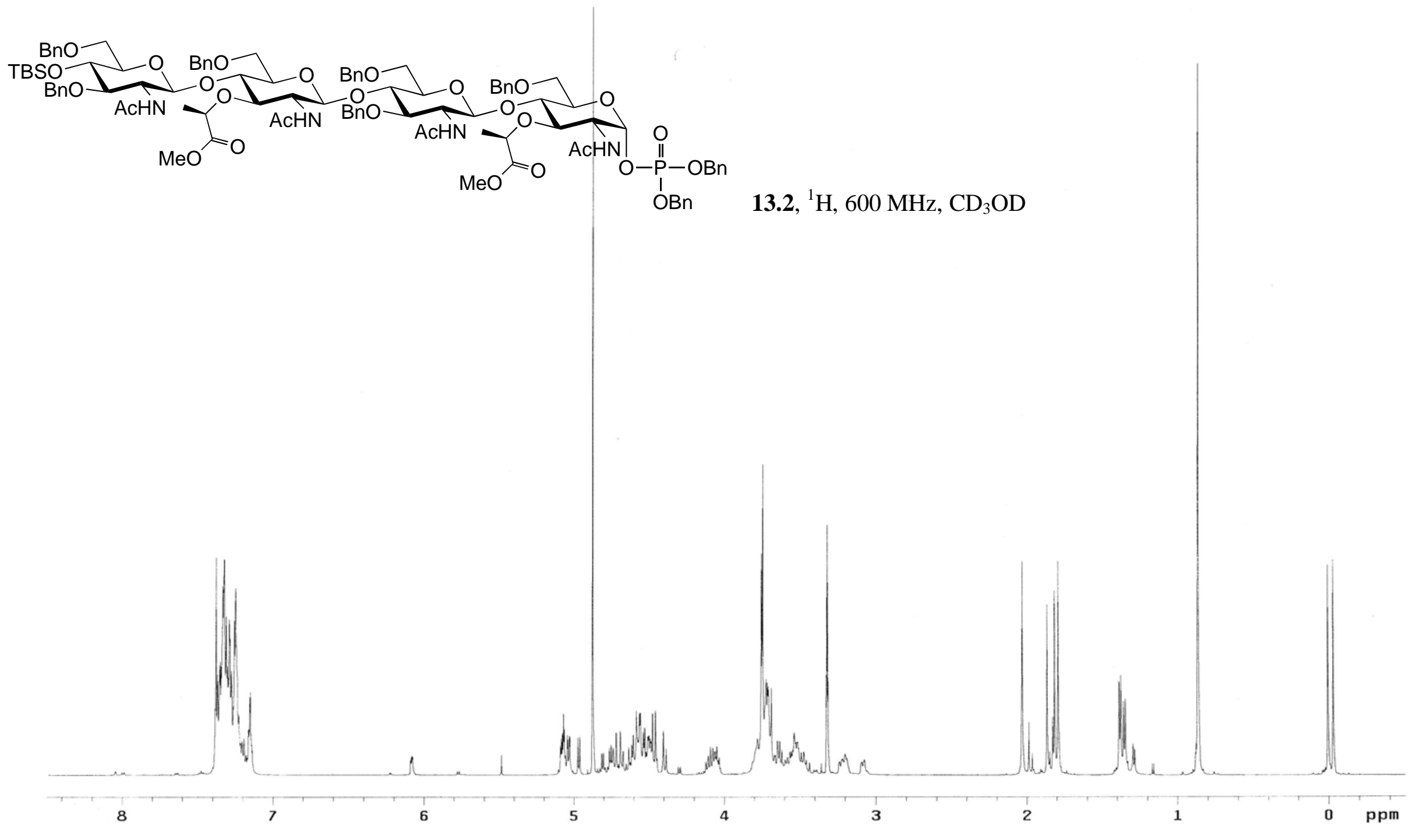


13.2, ${ }^{13} \mathrm{C}, 100 \mathrm{MHz}, \mathrm{CD}_{3} \mathrm{OD}$

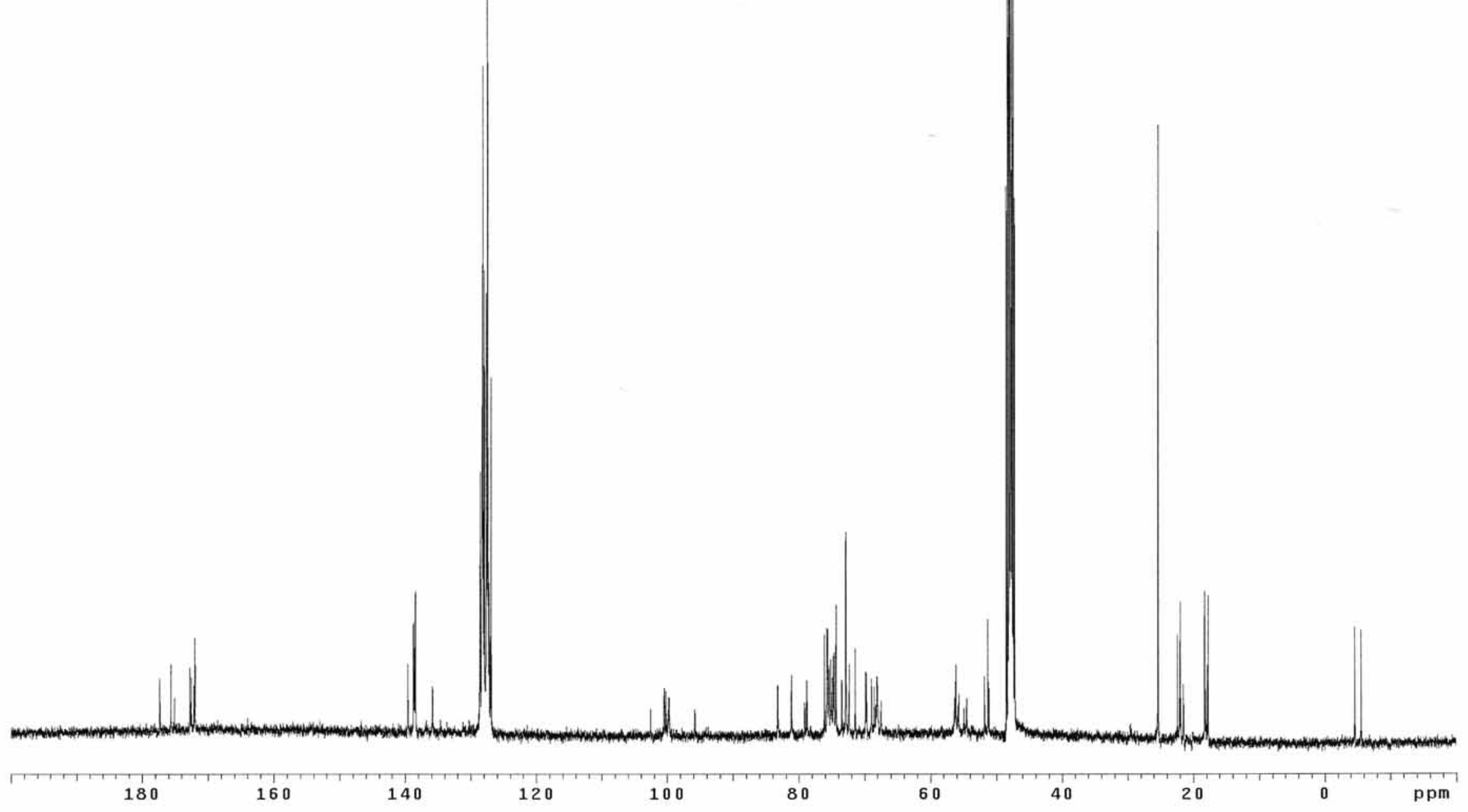




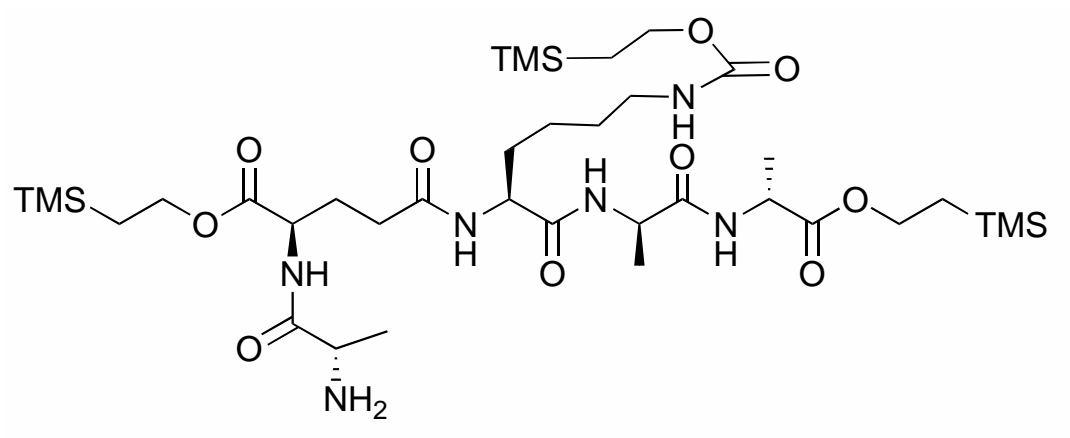

15, ${ }^{1} \mathrm{H}, 500 \mathrm{MHz}, \mathrm{CD}_{3} \mathrm{OD}$

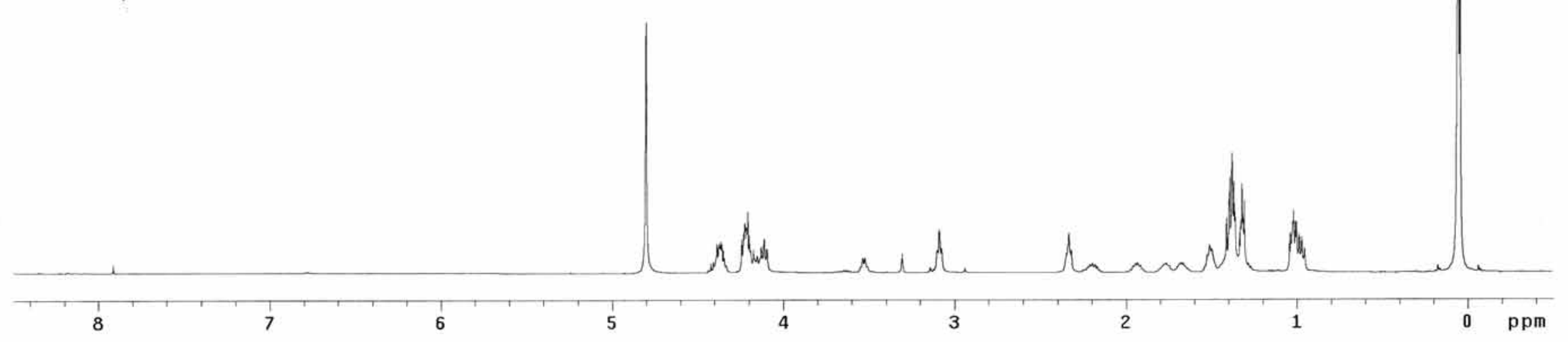


15, COSY, $500 \mathrm{MHz}, \mathrm{CD}_{3} \mathrm{OD}$

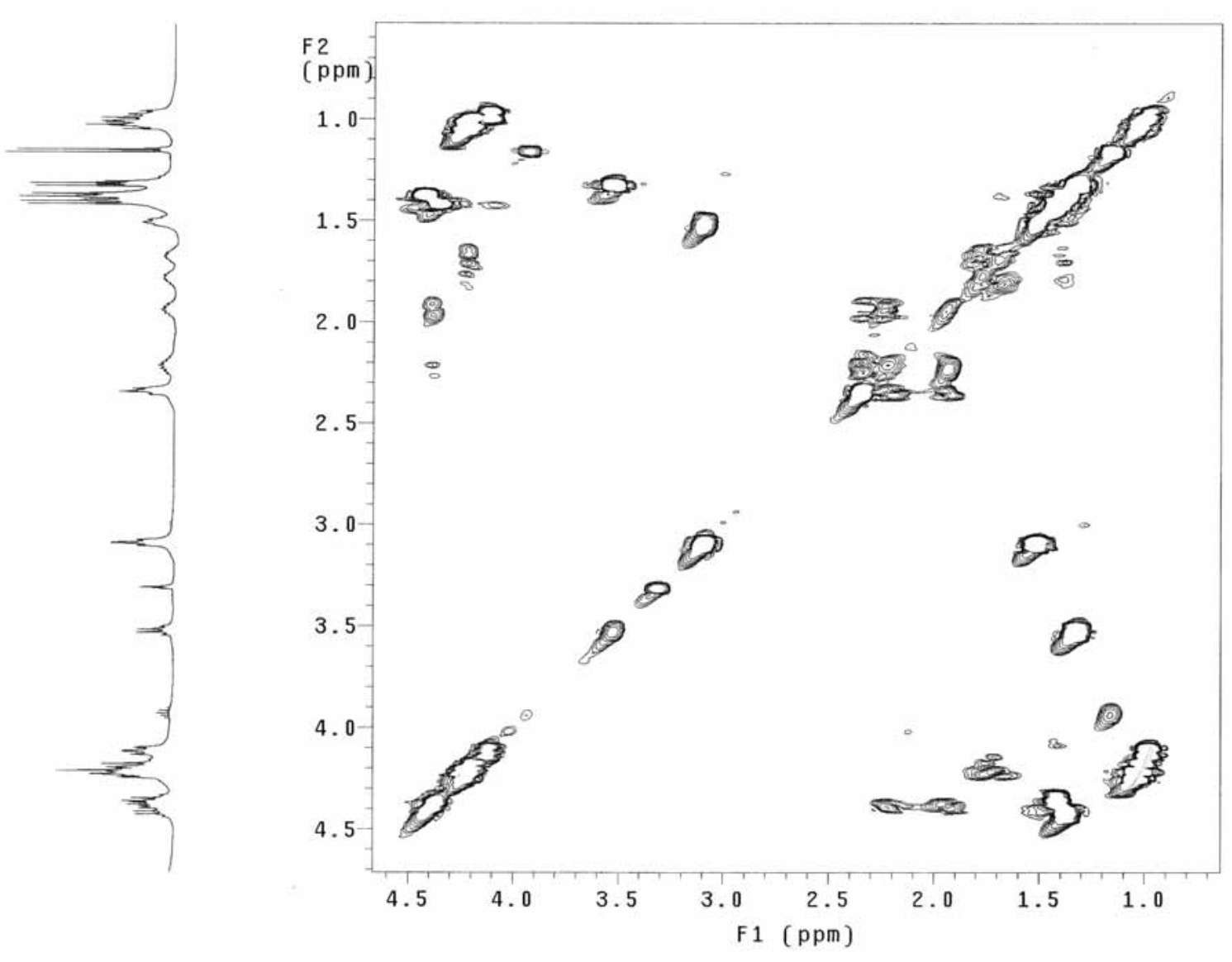


15, ${ }^{13} \mathrm{C}, 125 \mathrm{MHz}, \mathrm{CD}_{3} \mathrm{OD}$

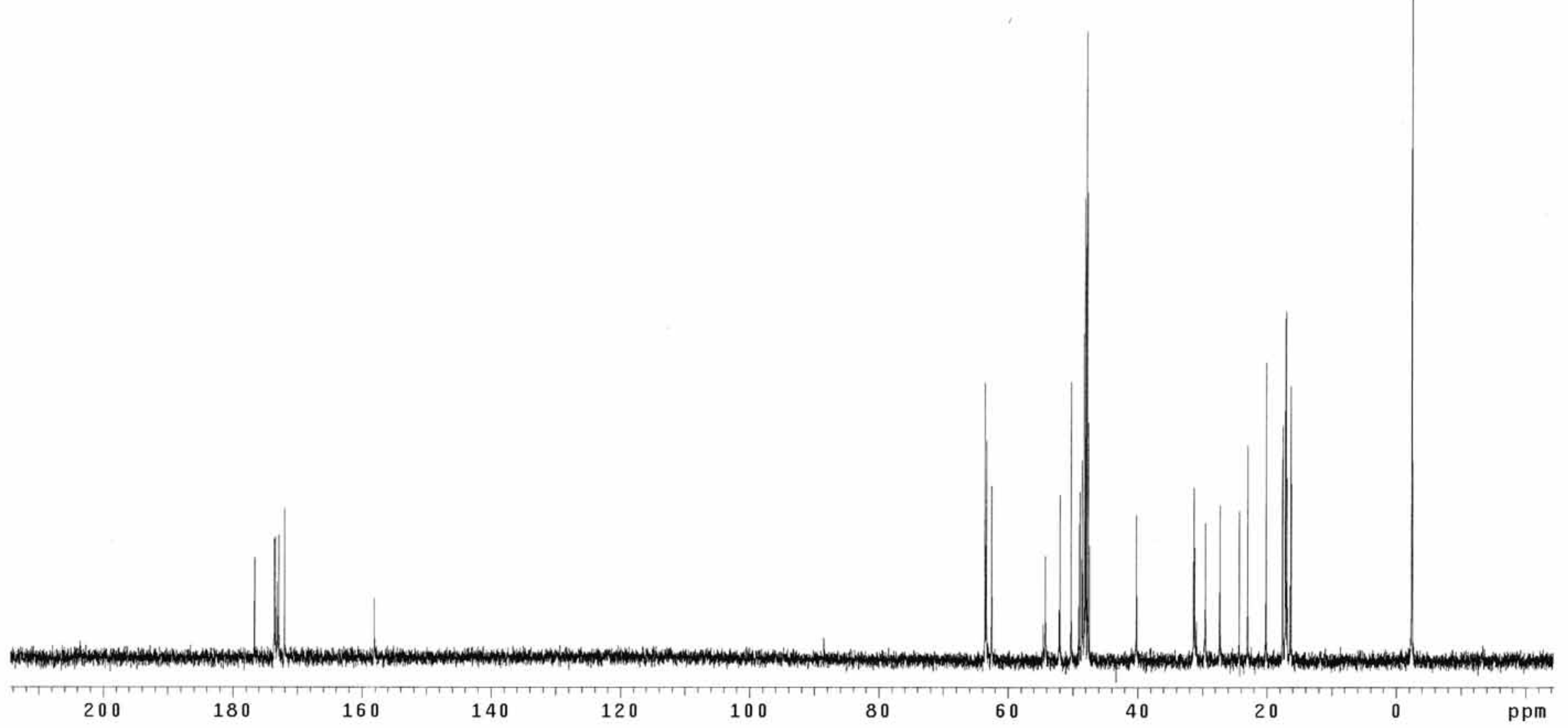




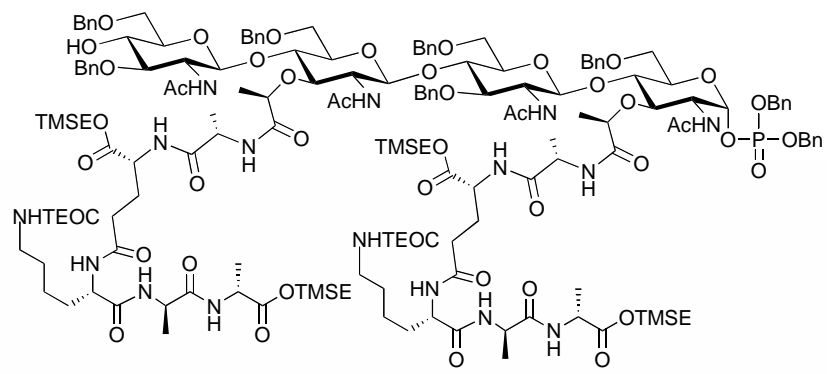

15.1, ${ }^{1} \mathrm{H}, 600 \mathrm{MHz}, \mathrm{CD}_{3} \mathrm{OD}$

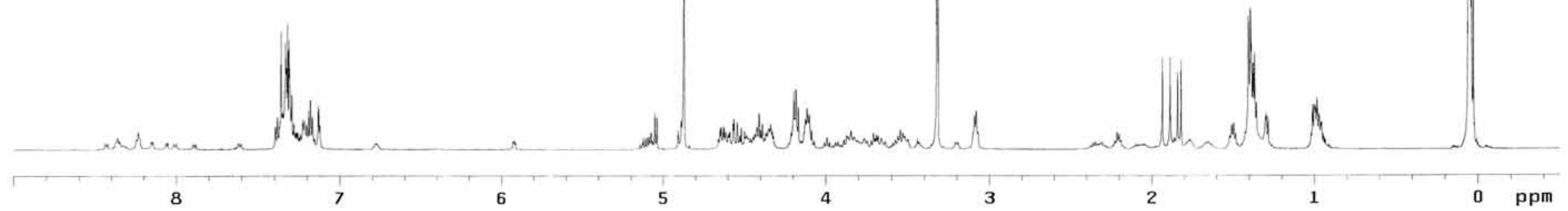

S2 38 
15.1, ${ }^{13} \mathrm{C}, 125 \mathrm{MHz}, \mathrm{CD}_{3} \mathrm{OD}$

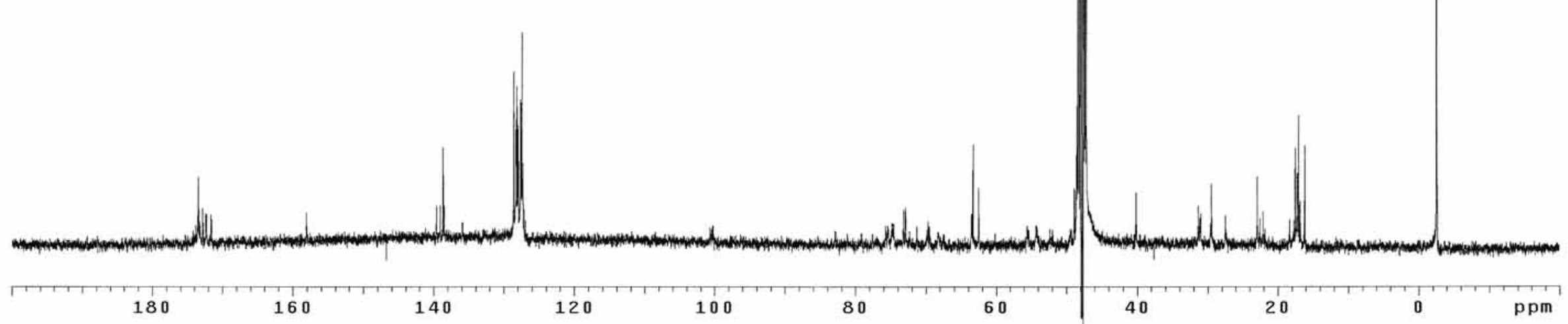




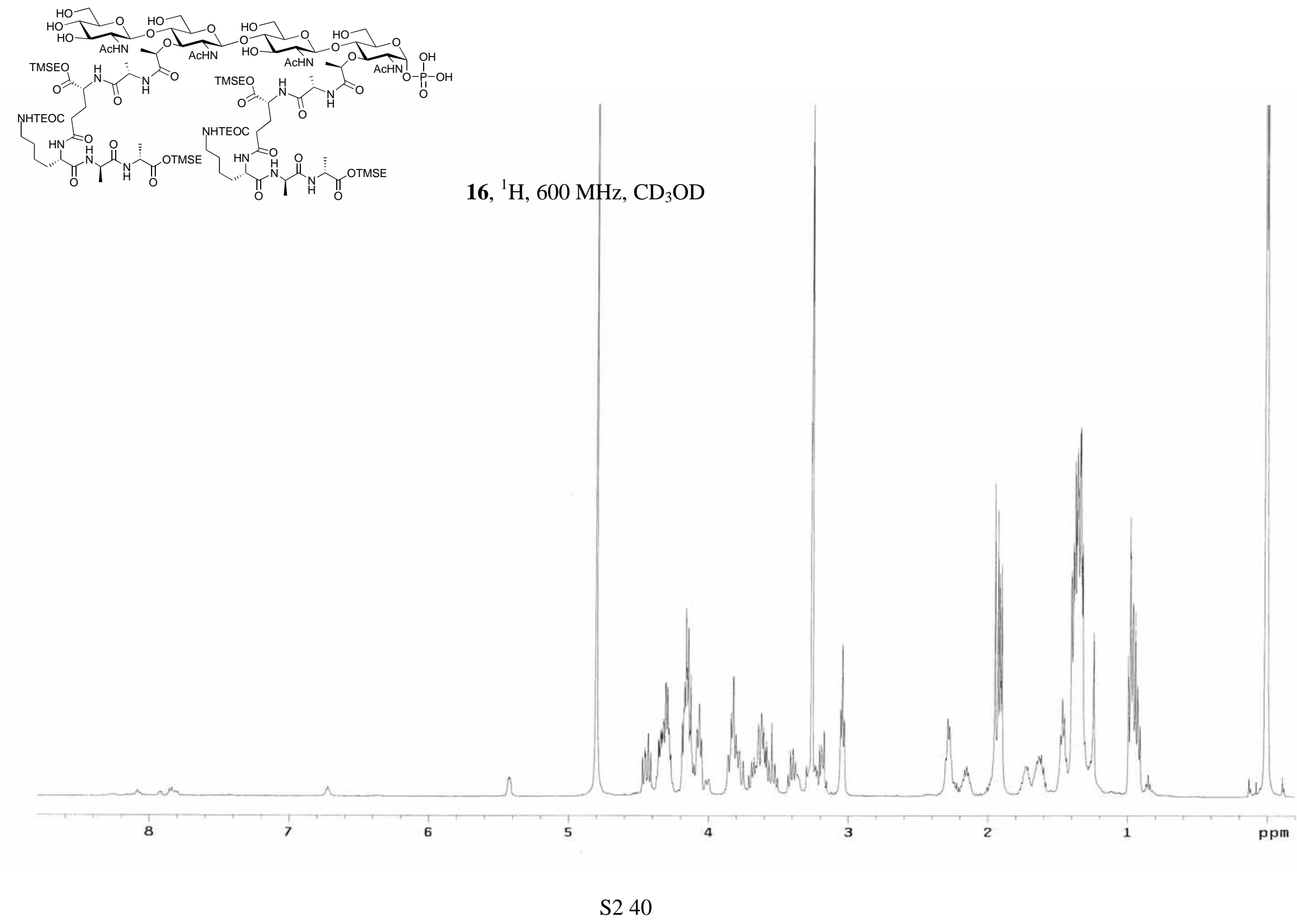


16, ${ }^{13} \mathrm{C}, 125 \mathrm{MHz}, \mathrm{CD}_{3} \mathrm{OD}$

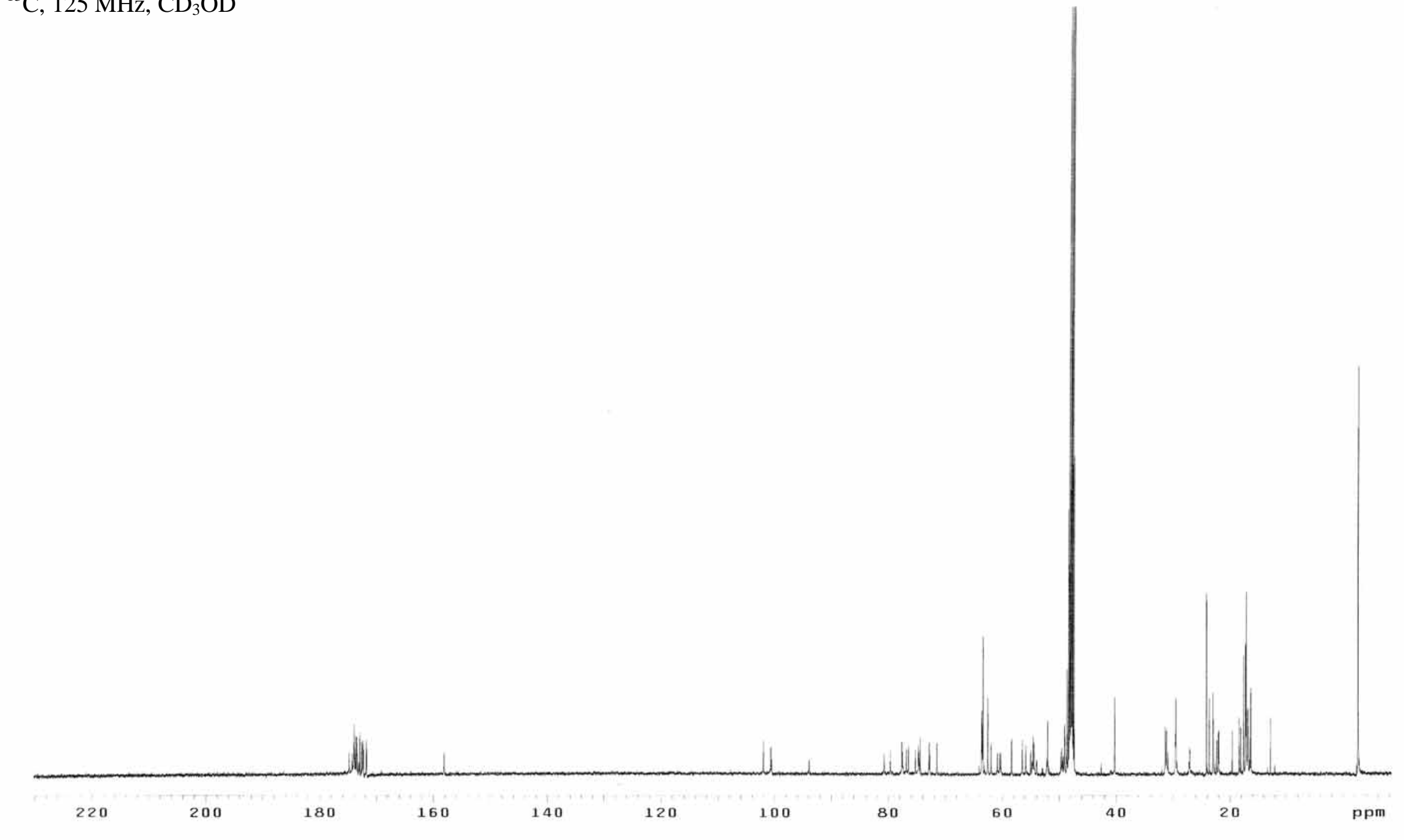


16, ${ }^{31} \mathrm{P}, 162 \mathrm{MHz}, \mathrm{CD}_{3} \mathrm{OD}$

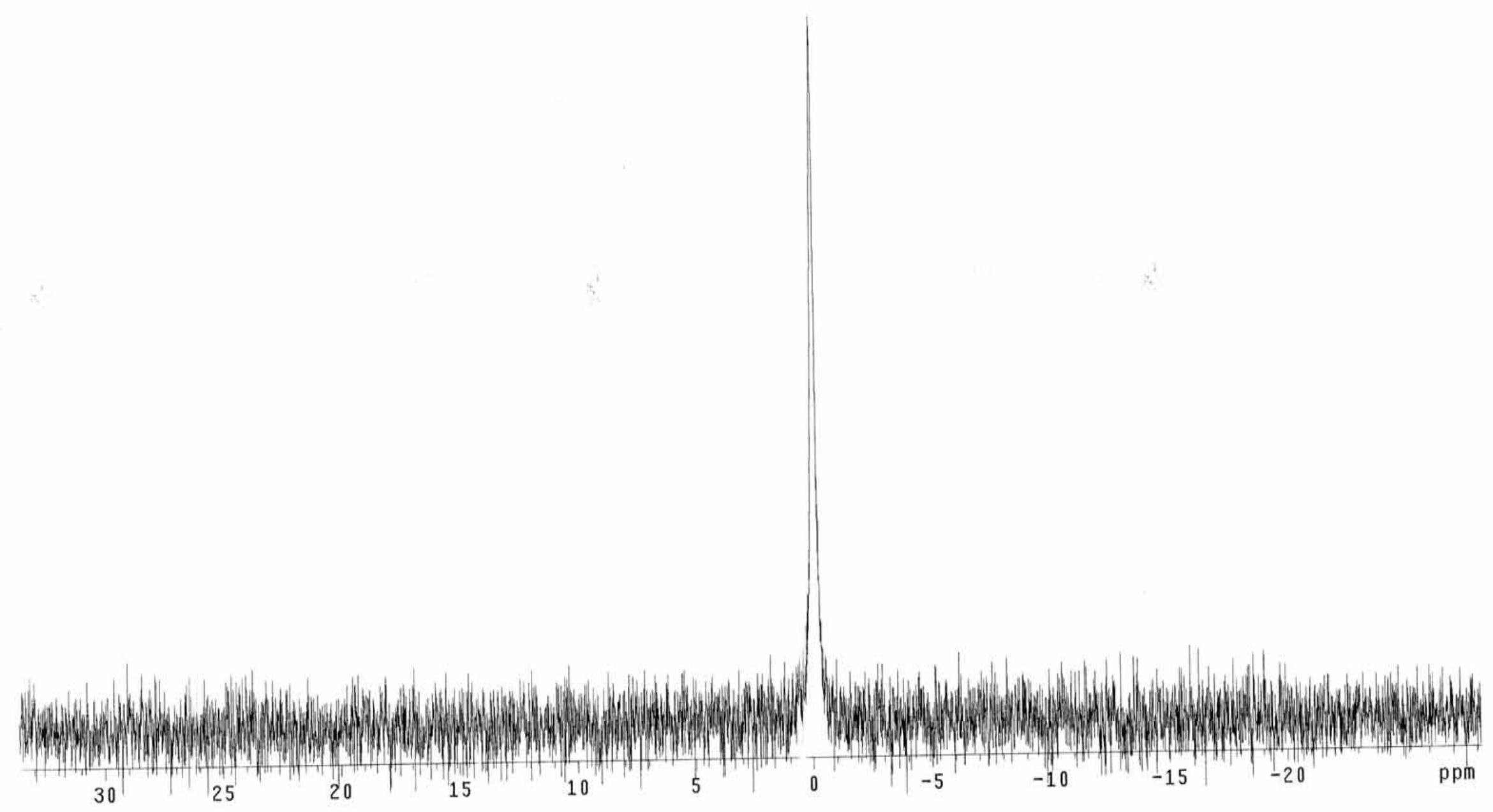

S2 42 


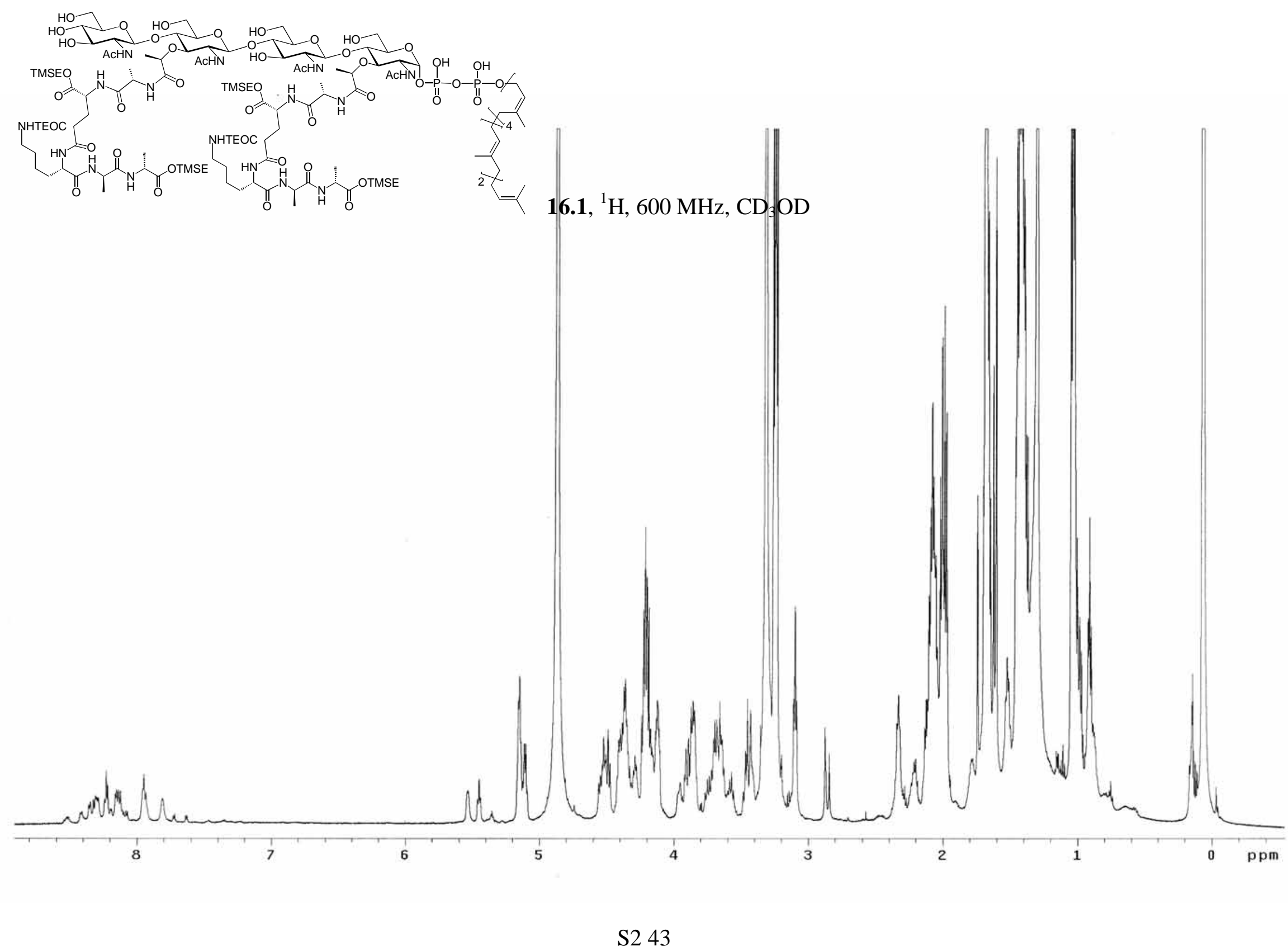


16, ${ }^{13} \mathrm{C}, 125 \mathrm{MHz}, \mathrm{CD}_{3} \mathrm{OD}$

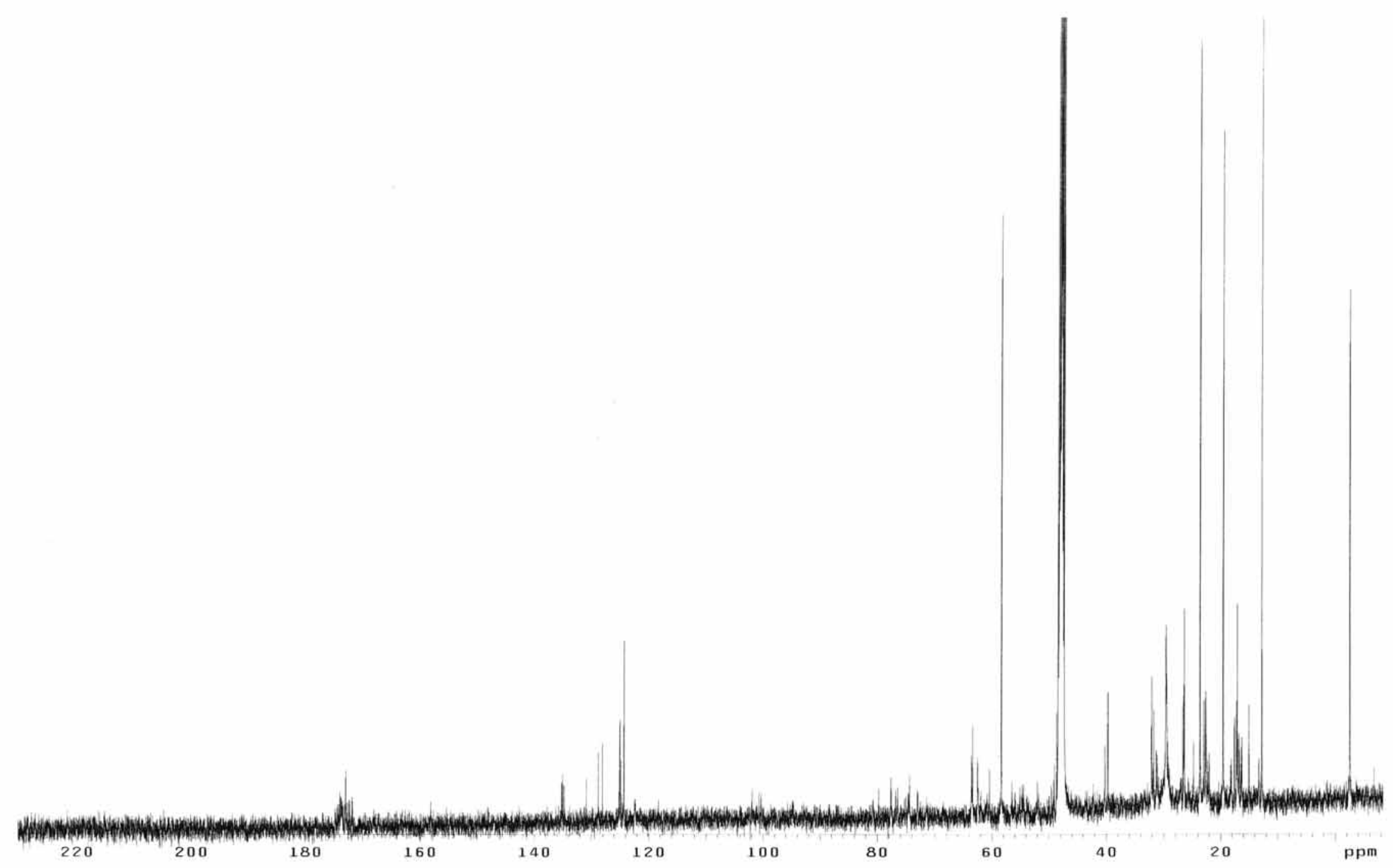


16.1, ${ }^{31} \mathrm{P}, 162 \mathrm{MHz}, \mathrm{CD}_{3} \mathrm{OD}$

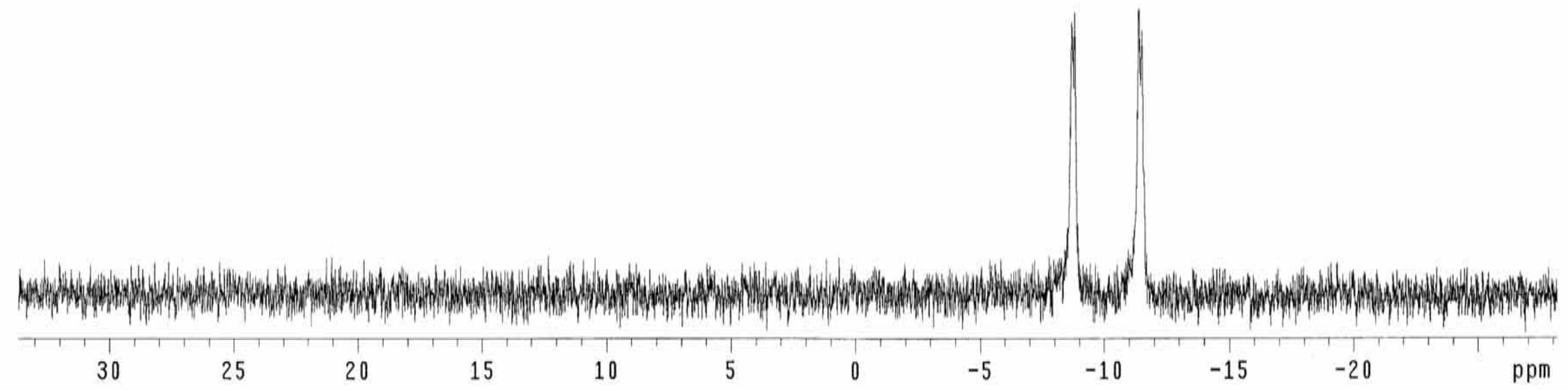




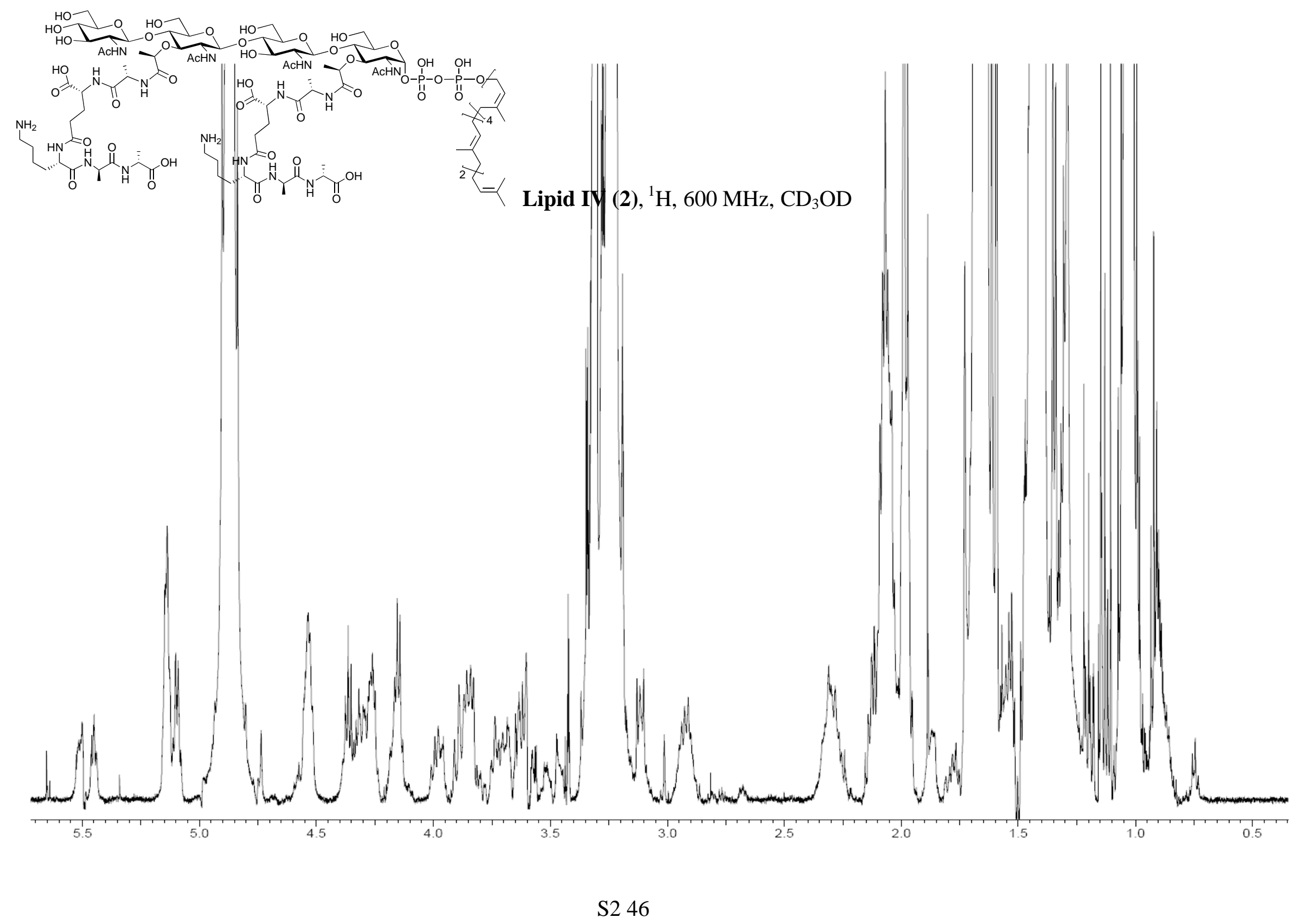


Lipid IV (2), ${ }^{31} \mathrm{P}, 162 \mathrm{MHz}, \mathrm{CD}_{3} \mathrm{OD}$

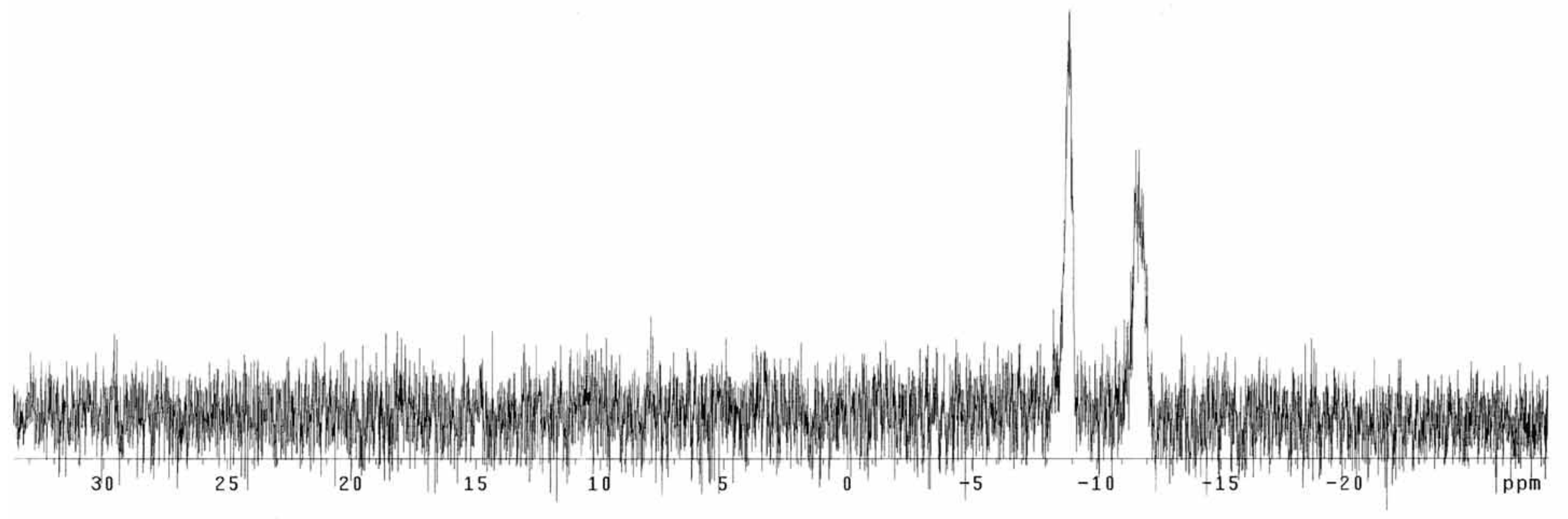




\section{Lipid IV (2), ESI-MS}

$\begin{array}{lccc}(\mathrm{M}-2) / 2 & 1274.9 & & \\ (\mathrm{M}-3) / 3 & 849.5 & 2 \mathrm{X}(\mathrm{M}-3) / 3 & 1700.3 \\ (\mathrm{M}-4) / 4 & 637.0 & & \end{array}$

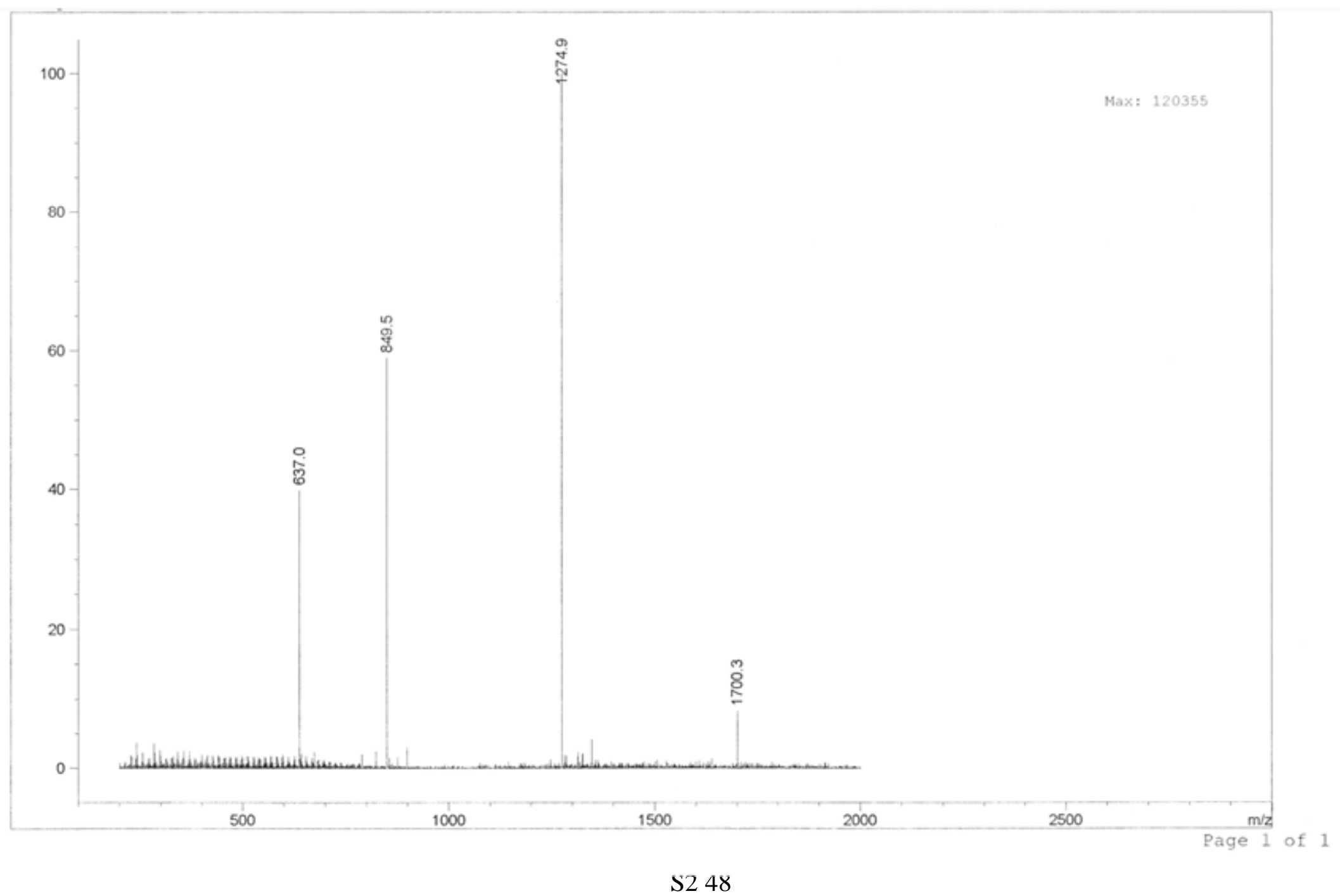




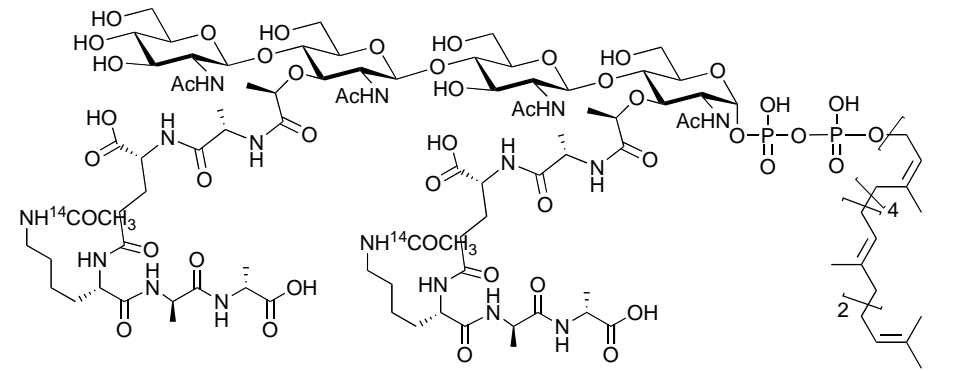

Normal Phase TLC: $\mathrm{CH}_{2} \mathrm{Cl}_{2}: \mathrm{MeOH}:$ aq.1\% $\mathrm{NH}_{3}(6: 3.5: 1)$

*Lipid IV (17)

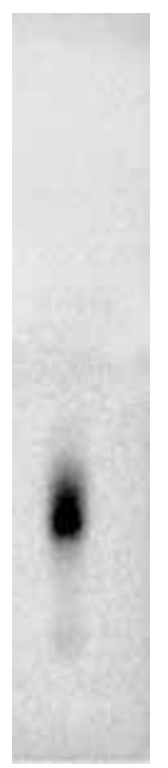

*Lipid IV (17)

Gel Electrophoresis: 20\% SDS-PAGE

12

Lane 1: $0.2 \mu \mathrm{L}$ C35 Lipid II ( $288 \mathrm{mci} / \mathrm{mmol})$

Lane 2: $1 \mu \mathrm{L} \quad{ }^{14} \mathrm{C}-17 \quad(22 \mathrm{mci} / \mathrm{mmol})$ 
ESI-MS:

$(\mathrm{M}-2) / 2 \quad 1316.9$

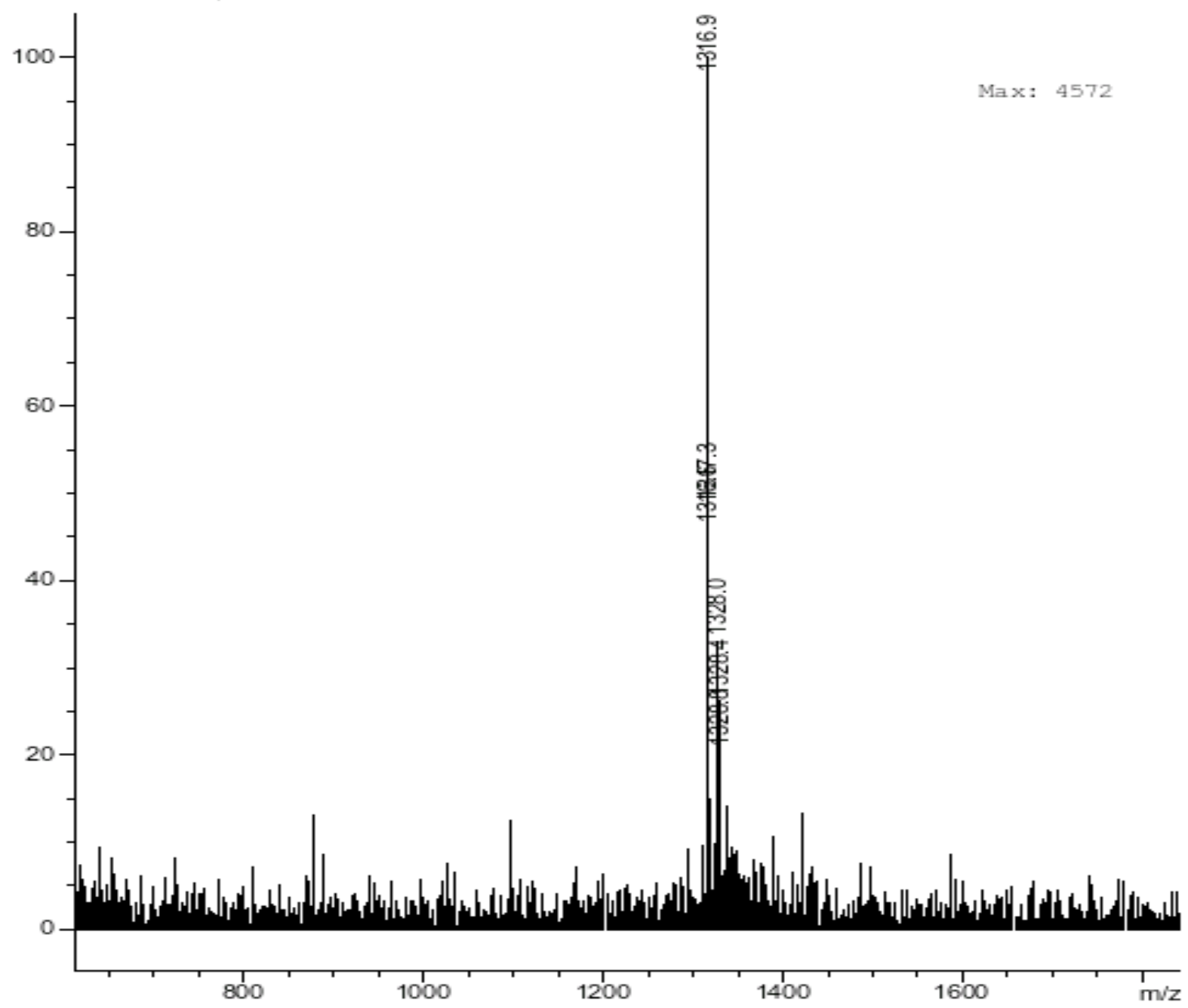

S2 50 